\title{
Scale dependence of entrainment-mixing mechanisms in cumulus clouds
}

Chunsong $\mathrm{Lu}^{1,2,3}$, Yangang $\mathrm{Liu}^{3}$, Shengjie Niu ${ }^{1}$, Satoshi Endo ${ }^{3}$

1. Collaborative Innovation Center on Forecast and Evaluation of Meteorological Disasters,

Key Laboratory for Aerosol-Cloud-Precipitation of China Meteorological Administration,

Key Laboratory of Meteorological Disaster of Ministry of Education, Nanjing University of Information Science and Technology, Nanjing 210044, China

2. State Key Laboratory of Numerical Modeling for Atmospheric Sciences and Geophysical Fluid Dynamics, Chinese Academy of Sciences, Beijing, 100029, China

3. Biological, Environmental and Climate Science Department, Brookhaven National Laboratory, Upton 11973, USA

Corresponding author: Chunsong $\mathrm{Lu}$

Address: Room 1005, Qixiang Bldg, No 219, Ningliu Road, Nanjing, Jiangsu, China 210044

Email: luchunsong110@gmail.com

Phone: 86-13851543016

This article has been accepted for publication and undergone full peer review but has not been through the copyediting, typesetting, pagination and proofreading process which may lead to differences between this version and the Version of Record. Please cite this article as doi: 10.1002/2014JD022265 


\section{Abstract}

This work empirically examines the dependence of entrainment-mixing mechanisms on the averaging scale in cumulus clouds using in situ aircraft observations during the RACORO field campaign. A new measure of homogeneous mixing degree is defined that can encompass all types of mixing mechanisms. Analysis of the dependence of the homogenous mixing degree on the averaging scale shows that, on average, the homogenous mixing degree decreases with increasing averaging scales, suggesting that apparent mixing mechanisms approach gradually from homogeneous mixing to extreme inhomogeneous mixing with increasing scales. The scale dependence can be well quantified by an exponential function, providing first attempt at developing a scale-dependent parameterization for the entrainment-mixing mechanism. Further examined are the influences of three factors on the scale dependence: droplet-free filament properties (size and fraction), microphysical properties (mean volume radius and liquid water content of cloud droplet size distributions adjacent to droplet-free filaments), and relative humidity of entrained dry air. It is found that the decreasing rate of homogeneous mixing degree with increasing averaging scales becomes larger with larger droplet-free filament size and fraction, larger mean volume radius and liquid water content, or higher relative humidity. The results underscore the necessity and possibility of considering averaging scale in representation of entrainment-mixing processes in atmospheric models.

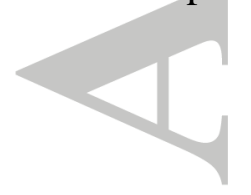




\section{Introduction}

Clouds have been considered as a major source of uncertainty in climate models because most cloud-related processes need to be represented with poorly understood parameterizations [Cess et al., 1989; Bony and Dufresne, 2005; Stephens, 2005; Wang et al., 2014; Zhang et al., 2014]. Among those processes that are parameterized the poorest is the turbulent entrainment-mixing process [Liu et al., 2002; von Salzen and McFarlane, 2002; Zhang, 2009; Romps and Kuang, 2010; de Rooy et al., 2013], although it has been long recognized that entrainment-mixing processes affect warm-rain initiation, aerosol indirect effect, cloud-climate feedback and remote sensing of cloud microphysical properties [Paluch and Baumgardner, 1989; Blyth, 1993; Yum, 1998; Xue and Feingold, 2006; Kim et al., 2008;

Del Genio and Wu, 2010; Ghan et al., 2011; Devenish et al., 2012; Kumar et al., 2012; Lu et al., 2013a].

Turbulent entrainment-mixing processes have been often studied with many conceptual models. The most used one is the homogeneous/inhomogeneous model [Baker et al., 1980; Baker et al., 1984; Freud et al., 2011]. In homogeneous entrainment-mixing process, all droplets are exposed to the same condition and evaporate simultaneously when dry air is entrained into cloud; in the extreme inhomogeneous entrainment-mixing process, some droplets evaporate completely while other droplets are not affected. Homogeneous mixing scenario is found more common in shallow cumulus clouds [Jensen et al., 1985; Gerber et al.,

2008; Lu et al., 2013c], whereas the inhomogeneous mixing scenario is more likely in stratocumulus clouds [Pawlowska et al., 2000; Burnet and Brenguier, 2007; Haman et al., 
2007; Lu et al., 2011]. Lehmann et al. [2009] pointed out that it was unclear whether the entrainment-mixing mechanism was predominantly homogeneous, inhomogeneous, or in between. Numerical simulations [Andrejczuk et al., 2009] and observations [Lehmann et al., 2009; Lu et al., 2011] showed that entrainment-mixing processes often fall between the above

\section{two extremes.}

The unsettling situation is also reflected in various modeling studies that examine the impacts of entrainment-mixing processes on cloud microphysical and optical/radiative properties. Some studies found that assuming different entrainment-mixing mechanisms caused a significant impact on cloud albedo [Grabowski, 2006; Chosson et al., 2007; Slawinska et al., 2008] and formation of large drops [Lasher-Trapp et al., 2005]. Morrison and Grabowski [2008] found that changing the entrainment-mixing mechanisms from the homogeneous to extreme inhomogeneous affected cloud microphysics and optical thickness, but such an impact was not as dramatic as in simulations discussed by Chosson et al. [2007] and Grabowski [2006]. Hill et al. [2009] found that assuming different entrainment-mixing mechanisms caused a small difference in cloud microphysics and optical depth. However, both Morrison and Grabowski [2008] and Hill et al. [2009] pointed out that the effect of mixing mechanisms could be more significant for simulations over the entire cloud life cycle, especially during dissipation when mixing processes are expected to dominate. Slawinska et al. [2012] found that the impact of the different entrainment-mixing mechanisms was significantly reduced, possibly due to the counteracting impacts of the subgrid-scale mixing and in-cloud activation, the mean characteristics of the entrained dry air, and numerical diffusion. In the above simulations, a given entrainment-mixing mechanism was assumed. 
Recently, Jarecka et al. [2013] explicitly treated mixing scenario in clouds. They found that the simulated homogeneity of mixing had a small impact on mean microphysical characteristics, which could be explained by the high humidity of the dry air involved in the subgrid-scale mixing processes.

A major challenge confronting the study of turbulent entrainment-mixing processes is that the related processes occur over a tremendous range of scales, from a cloud size down to the Kolmogorov microscale [Su et al., 1998]. In particular, Burnet and Brenguier [2007] found, using a stochastic model of entrainment mixing, that homogeneous entrainment-mixing mechanisms may appear to be extreme inhomogeneous due to the existence of droplet-free filaments and spatial averaging during measurements. Our recent observational study of the relationship between temperature and cloud droplet number concentration also suggested that the existence of droplet-free filament structure and spatial averaging during sampling partially contributed to the dominance of extreme inhomogeneous mixing in the stratocumulus clouds [Lu et al., 2011].

Further quantifying the scale dependence is obviously crucial for improving parameterization of entrainment-mixing processes in models of various resolutions. However, to the authors' knowledge, there has been no systematic investigation on the scale dependence using observational data, especially on factors influencing the scale dependence.

The objective of this work is to fill this gap by analyzing the data collected during the Routine AAF [Atmospheric Radiation Measurement (ARM) Aerial Facility] Clouds with Low Optical Water Depths (CLOWD) Optical Radiative Observations (RACORO) field campaign over the ARM Southern Great Plains (SGP) site near Lamont, Oklahoma, from 22 
January to 30 June 2009 [Vogelmann et al., 2012].

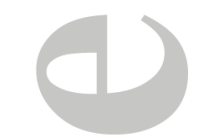

\section{RACORO data and analysis}

The dataset is the same as that used by $L u$ et al. [2012a], i.e., eight shallow cumulus flights (May 22, May 23, May 24, June 11, June 19, June 23, June 24, and June 26, 2009). The Twin Otter aircraft from the Center for Interdisciplinary Remotely-Piloted Aircraft Studies made comprehensive observations. Cloud droplet size distributions (CDSDs) were measured by Cloud and Aerosol Spectrometer (CAS) with $10 \mathrm{~Hz}$ and Forward Scatter Spectrometer Probe (FSSP) with $1 \mathrm{~Hz}$. The CAS probe measures aerosol particles and cloud droplets in 20 bins from 0.29 to $25 \mu \mathrm{m}$ (radius) and the FSSP probe measures cloud droplets in 20 bins from 1.1 to $15.1 \mu \mathrm{m}$ (radius). The calibrations of the instruments were carried out with spherical glass and polystyrene beads. The difference in optical properties of the glass and polystyrene beads as compared to water was taken into account in the calibration process. Figure 1 shows the comparison of LWC from the two instruments at $1 \mathrm{~Hz}$ in the 8 flights. The LWC from the CAS is calculated using droplets with bin-average radius larger than $1 \mu \mathrm{m}$ and LWC from the FSSP is calculated using all bins. Statistically, the LWC from the two independent measurements is consistent with each other, which gives confidence on the accuracy of the measurements. Since the CAS has a higher sampling rate than the FSSP, here only the results from the CAS will be used. Other cloud microphysical properties are also calculated using droplets with bin-average radius larger than $1 \mu \mathrm{m}$ from the CAS. The Cloud

Imaging Probe (CIP) was used to measure droplets within 7.50 - $781 \mu \mathrm{m}$ (radius) at a sampling rate of $1 \mathrm{~Hz}$. A Rosemount probe and the Diode Laser Hygrometer (DLH) [Diskin 
et al., 2002; Podolske et al., 2003] were used to measure temperature and water vapor at a sampling rate of $10 \mathrm{~Hz}$, respectively. Vertical velocity measurements were obtained with a 5-hole gust probe on the nose of the Twin Otter.

The criteria for selecting cloud records are: LWC $>0.001 \mathrm{~g} \mathrm{~m}^{-3}$ and $n>10 \mathrm{~cm}^{-3}$; the measured size distributions that are probably composed of large aerosols instead of cloud droplets can be eliminated by applying the both criteria [Deng et al., 2009]. The sampling area of the CAS is $11.1 \mathrm{~mm} \times 120 \mu \mathrm{m}$ and the true air speed is $\sim 50 \mathrm{~m} \mathrm{~s}^{-1}$. So the sampling volume at $10 \mathrm{~Hz}$ is $11.1 \mathrm{~mm}$ x $120 \mu \mathrm{m} \times 50 \mathrm{~m} \mathrm{~s}^{-1}$ x $0.1 \mathrm{~s}$, i.e., $6.66 \mathrm{~cm}^{-3}$. When number concentration is $10 \mathrm{~cm}^{-3}$, the number of droplets in the sampling volume is 66.6 . Thus the observations of each CDSD and microphysical properties should be reliable based on 66.6 droplets. In-cloud mean CIP drizzle LWC (radius $>25 \mu \mathrm{m}$ ) over the observation period smaller than $0.005 \mathrm{~g} \mathrm{~m}^{-3}$ is the criterion to identify non-drizzling clouds.

As stated in the paper by Lu et al. [2012a], only the data collected along horizontal legs are used. Non-drizzling growing cumulus clouds along a leg are selected with the following criteria: (1) CDSDs are thought to be in an individual cumulus cloud when the distance between them is less than $50 \mathrm{~m}$; (2) $80 \%$ of vertical velocity in an individual cloud is positive [Gerber et al., 2008; Lu et al., 2012c]; (3) to select relatively large clouds, the number of CDSDs must be larger than 30. (4) Cloud must be far enough from other clouds as determined with the following procedure. The temperature and water vapor mixing ratio in the environment are the mean values from the air that is $D$ to $2 D$ from the edge of the cloud core on both sides of the aircraft's cloud penetration. $D$ can be thought of representing the grid size within a high resolution model, and is set to be $10,20,30,40,50,100,300$, and $500 \mathrm{~m}$. The 
edge of a cloud core is defined as the point where vertical velocity changes from negative to positive for the first time, going from the cloud edge toward the cloud interior (see Figure 1a in $L u$ et al. [2012a] for details). If the edge of a cloud core is within $3 D$ from the edge of another cloud core on both the left and right sides, then this cloud is discarded. The selected clouds must satisfy the fourth criterion for different $D$ values at the same time. See Lu et al. [2012a] for more explanations on $D$ and cloud selection. A total of 186 growing cumulus clouds satisfy all the four criteria. Cloud depths of the 186 cumulus clouds are typically 200-500 m [Vogelmann et al., 2012]. The observation legs could be close to cloud top, in the middle of cloud and close to cloud base. The mean droplet concentration and its standard deviation are $923 \mathrm{~cm}^{-3}$ and $445 \mathrm{~cm}^{-3}$, respectively; the mean liquid water content and its standard deviation are $0.2 \mathrm{~g} \mathrm{~m}^{-3}$ and is $0.2 \mathrm{~g} \mathrm{~m}^{-3}$, respectively.

\section{Definition of homogeneous mixing degree and its calculation}

As stated in Introduction, entrainment-mixing mechanisms often fall between the two extremes---homogeneous mixing and extreme inhomogeneous mixing [Lehmann et al., 2009;

Lu et al., 2011]. A continuous measure is desirable that can encompass all types of mixing mechanisms. Lu et al. [2013b] defined such a measure named as homogeneous mixing degree ( $\psi$ ) based on the microphysical mixing diagram of $r_{\mathrm{vc}}{ }^{3} / r_{\mathrm{va}}{ }^{3} \mathrm{vs} n_{\mathrm{c}} / n_{\mathrm{a}}$, where $r_{\mathrm{vc}}$ and $r_{\mathrm{va}}$ are mean volume radius and adiabatic mean volume radius, respectively; $n_{\mathrm{c}}$ and $n_{\mathrm{a}}$ are number concentration and adiabatic number concentration, respectively. Here a mixing diagram of $r_{\mathrm{vc}}{ }^{3} / r_{\mathrm{va}}{ }^{3}$ vs LWC $\mathrm{C} / \mathrm{LWC}_{\mathrm{a}}$ instead of $n_{\mathrm{c}} / n_{\mathrm{a}}$ is used to define homogeneous mixing degree (Figure 2), where $\mathrm{LWC}_{\mathrm{c}}$ and $\mathrm{LWC}_{\mathrm{a}}$ are liquid water content and adiabatic liquid water content, 
respectively. The reason for replacing $n_{\mathrm{c}} / n_{\mathrm{a}}$ with $\mathrm{LWC}_{\mathrm{c}} / \mathrm{LWC}_{\mathrm{a}}$ is to minimize influences of aerosol and vertical velocity since number concentration is sensitive to them [Freud et al., 2008; Liu et al., 2008; Lu et al., 2012b; Mann et al., 2014], and to emphasize effects of entrainment-mixing mechanisms. Figure 2 conceptually illustrates the main states involved in an entrainment-mixing event. The states are numbered from 1 to 3 . State 1 is an adiabatic state with mean volume radius of $r_{\mathrm{va}}$ and liquid water content of $\mathrm{LWC}_{\mathrm{a}}$. State 2 is just after entrainment but before mixing and evaporation, which has mean volume radius of $r_{\mathrm{va}}$ and liquid water content of $\mathrm{LWC}_{\mathrm{a}} \times \chi ; \chi$ is the mixing fraction of adiabatic cloud. State 3 is the state where new saturation is achieved after mixing and evaporation, with mean volume radius of $r_{\mathrm{vc}}$ and liquid water content of $\mathrm{LWC}_{\mathrm{c}}$. Homogeneous mixing degree is defined as:

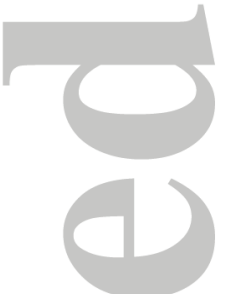

$$
\psi=\frac{m_{1}}{m_{2}}=\frac{1-\frac{r_{\mathrm{vc}}^{3}}{r_{\mathrm{va}}^{3}}}{1-\frac{1}{\chi} \frac{\mathrm{LWC}_{\mathrm{c}}}{\mathrm{LWC}_{\mathrm{a}}}} .
$$

where " $m_{1}$ " and " $m_{2}$ " represent the length of two lines shown in Figure 2, respectively; This definition is similar to the inhomogeneous fraction defined based on effective radius vs. liquid water content diagram in the paper by Gerber et al. [2008].

It is expected that $\psi$ ranges from 0 through 1 for isobaric entrainment mixing; a larger value of $\psi$ indicates a higher probability of homogeneous mixing. However, $\psi$ could be smaller than 0 or larger than 1 . For example, a cloud experiences inhomogeneous entrainment mixing below the aircraft horizontal leg; after inhomogeneous entrainment mixing, the diluted cloud is subject to an ascent and achieves the horizontal leg. The droplets in the diluted clouds have larger supersaturation and grow faster than those in adiabatic clouds because of smaller droplet number concentration and less competition for water vapor in 
diluted clouds. As a result, $r_{\mathrm{v}}$ is larger than $r_{\mathrm{va}}$ [Baker et al., 1980; Lasher-Trapp et al., 2005; Krueger, 2008; Lehmann et al., 2009; Lu et al., 2011] and $\psi$ is smaller than 0. In addition, $r_{\mathrm{v}}$ larger than $r_{\mathrm{va}}$ could also be related to collision-coalescence if droplets are large enough. Observation uncertainties of the properties that are needed in the calculation of homogeneous mixing degree may cause $\psi$ smaller than 0 or larger than 1 .

Similar to previous studies [Gerber et al., 2008; Lehmann et al., 2009; Lu et al., 2012c], $\chi$ is calculated based on the conservation of total water and energy during the isobaric mixing at the aircraft observation level:

$$
\begin{gathered}
q_{\mathrm{L}}+q_{\mathrm{vs}}(T)=\chi\left[q_{\mathrm{vs}}\left(T_{\mathrm{a}}\right)+q_{\mathrm{La}}\right]+(1-\chi) q_{\mathrm{ve}}, \\
c_{\mathrm{p}} T=c_{\mathrm{p}} T_{a} \chi+c_{\mathrm{p}} T_{\mathrm{e}}(1-\chi)-L_{\mathrm{v}}\left(q_{L a} \chi-q_{L}\right), \\
q_{\mathrm{vs}}(T)=0.622 \frac{e_{\mathrm{s}}(T)}{p-e_{s}(T)},
\end{gathered}
$$

where: $q_{\mathrm{La}}, T_{\mathrm{a}}$ and $q_{\mathrm{vs}}\left(T_{\mathrm{a}}\right)$ are, respectively, the liquid water mixing ratio, temperature and saturation vapor mixing ratio in the adiabatic cloud parcel; $q_{\mathrm{ve}}$ and $T_{\mathrm{e}}$ are, respectively, water vapor mixing ratio and temperature of the entrained dry air; $q_{\mathrm{L}}, T$ and $q_{\mathrm{vs}}(T)$ are, respectively, the liquid water mixing ratio, temperature, saturation vapor mixing ratio in cloud; $L_{\mathrm{v}}, c_{\mathrm{p}}, p$ and $e_{\mathrm{s}}$ are, respectively, the latent heat, specific heat capacity at constant pressure, air pressure and saturation vapor pressure at $T$. The input quantities for these equations are $q_{\mathrm{L}}, T_{\mathrm{e}}$, $q_{\mathrm{ve}}, q_{\mathrm{vs}}\left(T_{\mathrm{a}}\right)$ and $q_{\mathrm{La}}$; the output quantities are $q_{\mathrm{vs}}(T), T, \chi$ and $T_{\mathrm{a}}$.

The adiabatic water vapor mixing ratio $q_{\mathrm{La}}$ is derived from $\mathrm{LWC}_{\mathrm{a}}$ that is assumed to be the maximum liquid water content within a cumulus cloud core. The water vapor mixing ratio corresponding to $\mathrm{LWC}_{\mathrm{a}}$ is taken as the water vapor mixing ratio in the adiabatic cloud $\left[q_{\mathrm{vs}}\left(T_{\mathrm{a}}\right)\right]$ and the temperature $\left(T_{\mathrm{a}}\right)$ in the adiabatic cloud is calculated from $\left[q_{\mathrm{vs}}\left(T_{\mathrm{a}}\right)\right]$, assuming 
saturation in the adiabatic cloud. $T_{\mathrm{e}}$ and $q_{\mathrm{ve}}$ in entrained dry air are the mean values from the air that is $D$ to $2 D$ from the edge of a cloud core.

In the calculation of $\psi, r_{\mathrm{va}}$ is needed and obtained by:

$$
r_{\text {va }}=\left(\frac{\mathrm{LWC}_{\mathrm{a}}}{4 / 3 \pi \rho n_{\mathrm{a}}}\right)^{1 / 3},
$$

where $\rho$ is the water density, $n_{\mathrm{a}}$ is assumed to be the maximum number concentration in an individual cloud. Note that there are uncertainties in the estimated values of $\mathrm{LWC}_{\mathrm{a}}, n_{\mathrm{a}}$ and $r_{\mathrm{va}}$, and the discussion about such uncertainty effects on $\psi$ is deferred to Section 4.1.

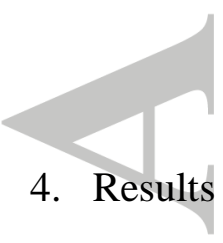

\subsection{Scale dependence of homogeneous mixing degree}

To study the dependence of homogeneous mixing degree on the averaging scale, the averaging time window is set to be $0.1,0.2,0.3,0.4,0.5,0.6,0.7,0.8,0.9,1,2,3,4,5,6,7,8$, $9,10,15,20,30,40,50$ and $60 \mathrm{~s}$. The homogeneous mixing degrees are calculated in the 186 growing cumulus clouds using the method described above at these different temporal averaging scales. Two methods are used to estimate mean homogeneous mixing degree in each cloud. In the first method, mean values of mean volume radius and liquid water content in each cloud are used in the calculation of homogeneous mixing degree. The mean values of mean volume radius and liquid water content are calculated using new CDSDs after averaging in each cloud. In the second method, instantaneous homogeneous mixing degree is calculated for each new CDSD after averaging with equation (1), and then the mean value of homogeneous mixing degrees of all new CDSDs in each cloud is taken to be the mean homogeneous mixing degree in each cloud. The results from the two methods are close to 
each other, and thus only the results from the first method are used in the following analysis.

Figure 3 shows the relationship between the homogeneous mixing degree and the averaging time window $(t)$ for $D=50 \mathrm{~m}$; the upper $\mathrm{x}$-axis also shows the averaging distance estimated from the product of the averaging time and the aircraft flight speed $\left(\sim 50 \mathrm{~m} \mathrm{~s}^{-1}\right)$. It is evident that $\psi$ decreases with increasing averaging scales. This result is consistent with previous studies [Burnet and Brenguier, 2007; Lu et al., 2011]. The standard error of the mean decreases as the averaging scale increases. Note that for different averaging scales, the sample number of mean homogeneous mixing degree is the same, i.e., 186, because each cloud has one mean homogeneous mixing degree. When $\psi$ decreases as the averaging scale increases, the difference of $\psi$ among 186 clouds also becomes smaller for the larger averaging scale; correspondingly, the standard error of the mean decreases. The results for other $D$ values are similar and thus not shown.

To further quantify the scale dependence, the relationship between $\psi$ and $t$ in Figure 3 is fitted by the exponential function:

$$
\psi=a+b \times c^{t}
$$

where $a, b$ and $c$ are three fitting parameters and $t$ is the averaging time. The results for other $D$ values can also be fitted well by equation (4). It is interesting to note that when $D$ increases from $10 \mathrm{~m}$ to $500 \mathrm{~m}$, the parameter $c$ remains in the range of 0.90 to 0.91 ; the parameter $a$ decreases only slightly from 0.36 to 0.33 , and the parameter $b$ changes the most, decreasing from 0.56 to 0.40 when $D$ increases from 10 to $500 \mathrm{~m}$. The variations of $a$ and $b$ cause a decrease in $\psi$ with increasing $D$, which is related to relative humidity in the dry air. As shown in Figure 3 of $L u$ et al. [2012a], the variation of $D$ manifests primarily in the variation of 
relative humidity, which significantly decreases as $D$ increases from 10 to $500 \mathrm{~m}$. There is much less variation in temperature, only increasing $\sim 0.7 \mathrm{~K}$ as $D$ increases from 10 to $500 \mathrm{~m}$. Detailed analysis on the effect of relative humidity on homogeneous mixing degree is deferred to Section 4.2.4. In addition, different clouds have different cloud sizes, horizontal penetration heights above cloud base, cloud dynamics and different moist shells. Considering that different clouds may entrain dry air at different values of $D$, we also examine the relationship between $\psi$ and $t$ assuming that the entrained dry air is from 10-1000 $\mathrm{m}$ away from the cloud core edge. This relationship exhibits similar scale dependence and is close to that for $D=300 \mathrm{~m}$.

There exist two sources of uncertainty in the homogeneous mixing degree derived above: one from the measurement uncertainty of the variables needed as inputs in the calculation of homogeneous mixing degree, and the other from the adiabatic cloud core assumption. This section serves to analyze the potential effects of the two sources of uncertainty.

The measurement errors of temperature, water vapor mixing ratio, and liquid water content are $\quad \pm 0.5^{\circ} \mathrm{C} \quad[\mathrm{http}: / / \mathrm{www} 2$. emersonprocess.com/siteadmincenter/ pm\%20rosemount\%20documents/00825-0300-2654.pdf], $\pm 3 \%$ [Podolske et al., 2003] and $\pm 38 \%$ [Darrel Baumgardner, personal communications], respectively. The uncertainty in $\psi$ is estimated using three values for each input variable. Taking temperature for example, the three values used are the observed temperature and observed $\pm 0.5^{\circ} \mathrm{C}$ at a given level. The combination of the three variables produces 27 sets of input. The relationship between $\psi$ and $t$ for $D=50 \mathrm{~m}$ is plotted (not shown); there are $186 \times 27$ samples for each averaging time and distance window. The reason to use $D=50 \mathrm{~m}$ is that the relative humidity in the dry air for $D$ 
$=50 \mathrm{~m}$ is in the middle among the relative humidity for all $D$ values. The relative humidity for $D=10,50$ and $500 \mathrm{~m}$ are $91.2 \%, 84.3 \%$ and $74.5 \%$; the mean value of $91.2 \%$ and $74.5 \%$ is close to $84.3 \%$. Thus the result for $D=50 \mathrm{~m}$ should be representative and is used in the later analyses. The relationship between $\psi$ and $t$ considering the measurement errors of temperature, water vapor mixing ratio and liquid water content can be fitted by

$$
\psi=0.32+0.56 \times 0.90^{t}
$$

which is quite close to the function in Figure 3

$$
\psi=0.34+0.52 \times 0.90^{t}
$$

The standard errors of the mean in the relationship between $\psi$ and $t$ considering the measurement errors are in the range of 0.0027 to 0.018 , with the mean of 0.011 . Therefore, the examination of scale dependence of homogeneous mixing in this study is not significantly affected by the measurement errors.

The adiabatic cloud core assumption could be another error source for homogeneous mixing degree. The assumed $\mathrm{LWC}_{\mathrm{a}}$ along a horizontal leg might be less than the true $\mathrm{LWC}_{\mathrm{a}}$ due to possible influence of entrainment-mixing processes. Other approaches for estimating a cloud-base height and $\mathrm{LWC}_{\mathrm{a}}$ have been reported in the literature, but they are not applicable here. For example, a cloud-base height can be estimated using moisture and temperature from aircraft observations in the dry air below cloud, from surface stations, or obtained from some direct measurements [e.g., Clothiaux et al., 2000]. A cloud-base height can also be estimated by fitting peak LWC values from different aircraft observation levels with a linear profile [e.g., Gerber et al., 2008]. LWC ${ }_{\mathrm{a}}$ can be calculated with the cloud-base height. Unfortunately, these approaches are not applicable in RACORO because cloud-base heights varied 
significantly during a flight [Vogelmann et al., 2012], and it is not appropriate to assume a constant cloud-base height for different cumulus clouds in a flight. In addition, the cumulus clouds analyzed here are shallow and the properties of the shallow cumuli may change during the time when the aircraft changes its altitude for observations at different levels.

In addition to the uncertainty of $\mathrm{LWC}_{\mathrm{a}}$, the other two properties, $r_{\mathrm{va}}$ and $n_{\mathrm{a}}$, have similar problems due to possible effect of entrainment-mixing processes. Assume that the true adiabatic cloud has $\mathrm{LWC}_{\mathrm{aa}}, r_{\mathrm{vaa}}$ and $n_{\mathrm{aa}}$; during the entrainment-mixing processes, $\mathrm{LWC}_{\mathrm{aa}}, r_{\mathrm{vaa}}$ and $n_{\mathrm{aa}}$ become $\mathrm{LWC}_{\mathrm{a}}, r_{\mathrm{va}}$ and $n_{\mathrm{a}}$, respectively. To study the sensitivity of homogeneous mixing degree to the uncertainty of adiabatic cloud core assumption, $\mathrm{LWC}_{\mathrm{aa}}$ is assumed to be 1.25 times of $\mathrm{LWC}_{\mathrm{a}}$. Since $\mathrm{LWC}_{\mathrm{a}}, r_{\mathrm{va}}$ and $n_{\mathrm{a}}$ are known from observation, $r_{\mathrm{vaa}}$ and $n_{\mathrm{aa}}$ can be calculated by:

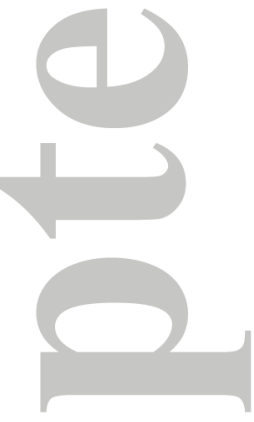

$$
\begin{gathered}
r_{\mathrm{vaa}}=\frac{r_{\mathrm{va}}}{\left[1-\psi_{\mathrm{aa}}\left(1-\frac{1}{\chi_{\mathrm{aa}}} \frac{\mathrm{LWC}_{\mathrm{a}}}{\mathrm{LWC}_{\mathrm{aa}}}\right)\right]^{1 / 3}}, \\
n_{\mathrm{aa}}=\frac{\mathrm{LWC}_{\mathrm{aa}}}{4 / 3 \pi \rho r_{\mathrm{vaa}}^{3}},
\end{gathered}
$$

respectively, where $\chi_{\mathrm{aa}}$ and $\psi_{\mathrm{aa}}$ are, respectively, the mixing fraction and homogeneous mixing degree in the entrainment-mixing process affecting assumed adiabatic cloud core. Equation (7) is derived from equation (1). $\chi_{\text {aa }}$ can be calculated using equation (2) with some properties replaced. $q_{\mathrm{La}}, T_{\mathrm{a}}$ and $q_{\mathrm{vs}}\left(T_{\mathrm{a}}\right)$ are replaced by $q_{\mathrm{Laa}}, T_{\mathrm{aa}}$ and $q_{\mathrm{vs}}\left(T_{\mathrm{aa}}\right)$, i.e., the liquid water mixing ratio, temperature and saturation vapor mixing ratio in the true adiabatic cloud core, respectively; $q_{\mathrm{L}}, T$ and $q_{\mathrm{vs}}(T)$ are replaced by $q_{\mathrm{La}}, T_{\mathrm{a}}$ and $q_{\mathrm{vs}}\left(T_{\mathrm{a}}\right)$, respectively.

To calculate $r_{\text {vaa }}$ and $n_{\text {aa }}$ using equations (7) and (8), $\psi_{\text {aa }}$ is needed but unknown. Three (C2014 American Geophysical Union. All rights reserved. 
assumptions of entrainment-mixing mechanism are made. Assumption One: $\psi_{\mathrm{aa}}$ for different $t$ is, respectively, the same as $\psi$ shown in Figure 3. Assumption Two: $\psi_{\mathrm{aa}}$ is equal to the mean $\psi$ for $t=0.1 \mathrm{~s}$ in Figure 3, i.e., the maximum value of the mean $\psi$. Assumption Three: $\psi_{\mathrm{aa}}$ is equal to the mean $\psi$ for $t=60 \mathrm{~s}$ in Figure 3, i.e., the minimum value of the mean $\psi$. With $\psi_{\text {aa }}$ and $\chi_{\text {aa }}, r_{\text {vaa }}$ can be calculated. Replacing $r_{\mathrm{va}}$ and $\mathrm{LWC}_{\mathrm{a}}$ in equation (1) with $r_{\mathrm{vaa}}$ and $\mathrm{LWC}_{\mathrm{aa}}$, respectively, new homogeneous mixing degrees are calculated. Figure 4a shows homogeneous mixing degree as a function of $t$ under different $\psi_{\text {aa }}$ assumptions for $D=50 \mathrm{~m}$;

Figure $4 \mathrm{~b}$ enlarges the part of Figure $4 \mathrm{a}$ for $t<10 \mathrm{~s}$ to show the results clearer. For Assumption One, the relationship between homogeneous mixing degree and $t$ (the green line) is similar to the reference (the red line), where the $\mathrm{LWC}_{\mathrm{aa}}$ is assumed to be the maximum liquid water content (Figure 3). The fitting equations indicate that the only difference between the two fitting lines is the intercept. The difference of the mean $\psi$ with respect to the reference is in the range of 0.019 to 0.031 for different $t$, and the mean difference is 0.026 . For Assumptions Two and Three, the deviation of the mean $\psi$ with respect to the reference has the mean values of 0.067 and -0.042 , respectively. Furthermore, the fitting functions for different assumptions have similar shapes, because the parameter $c$ in equation (4) is around 0.90. Therefore, the adiabatic cloud core assumption could affect homogeneous mixing degree to some extent, but the homogeneous mixing degree calculated in this study is still reliable.

Another support for assuming adiabatic cloud core is that, Lu et al. [2014] also made the same assumption and found that homogeneous mixing degree is positively correlated with transition scale number, consistent with the theoretical expectation. The transition scale 
number, defined by Lu et al. [2011], theoretically represents the probability of homogeneous entrainment-mixing mechanisms.

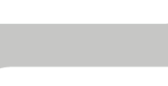

4.2 Examination of factors affecting the scale dependence

4.2.1 Strength of scale dependence

To inspect the factors that affect the scale dependence, we use the difference $\psi_{1}-\psi_{0.1}$ and the ratio $\psi_{1} / \psi_{0.1}$ for $D=50 \mathrm{~m}$, to gauge the strength of the scale dependence. The homogeneous mixing degrees for $0.1 \mathrm{~s}\left(\psi_{0.1}\right)$ and for $1 \mathrm{~s}\left(\psi_{1}\right)$ are used because $0.1 \mathrm{~s}$ and $1 \mathrm{~s}$ are two sampling rates that are commonly used in in-situ aircraft measurements, and the CDSDs averaged over $0.1 \mathrm{~s}$ and $1 \mathrm{~s}$ have more samples than for other averaging time windows, e.g., $10 \mathrm{~s}$. Figures $5 \mathrm{a}$ and $5 \mathrm{~b}$ show the probability density functions of $\psi_{1}-\psi_{0.1}$ and $\psi_{1} / \psi_{0.1}$, respectively. Generally speaking, the difference $\psi_{1}-\psi_{0.1}$ is negative and the ratio $\psi_{1} / \psi_{0.1}$ is less than 1 , confirming the previous results that entrainment-mixing mechanisms tend to be more inhomogeneous when the averaging scale is larger or sampling rate is lower [Burnet and Brenguier, 2007; Lu et al., 2011] and Figure 3.

Figure 5 also indicates that both $\psi_{1}-\psi_{0.1}$ and $\psi_{1} / \psi_{0.1}$ have wide ranges of values, suggesting that the scale dependence of entrainment-mixing mechanisms has different strength in different clouds. Next examined are the effects of several plausible factors on the strength of the scale dependence of entrainment-mixing mechanisms.

4.2.2 Effect of droplet-free filaments

One factor that may affect entrainment-mixing processes and their scale dependence is 
droplet-free filament, as measured by mean droplet-free filament size, sum of droplet-free filament size and droplet-free filament fraction $(F)$. Figure 6 shows the relationships of $\psi_{1}-\psi_{0.1}$ and $\psi_{1} / \psi_{0.1}$ with mean droplet-free filament size, sum of droplet-free filament size, and droplet-free filament fraction $F$, respectively. In an individual cloud, there could be several droplet-free filaments. Each droplet-free filament size is calculated as follows. Since the sampling rate is $10 \mathrm{~Hz}$, sampling time difference $\left(t_{\mathrm{d}}\right)$ of two neighboring CDSDs is $0.1 \mathrm{~s}$ if there is no droplet-free filament between them. If filament exists, $t_{\mathrm{d}}$ should be larger than $0.1 \mathrm{~s}$. The droplet-free filament size is estimated with the product of " $t_{\mathrm{d}}-0.1$ " and the aircraft speed $\left(\sim 50 \mathrm{~m} \mathrm{~s}^{-1}\right)$. The sum of droplet-free filament size measures the total length of all the droplet-free filaments, and droplet-free filament fraction in an individual cloud is calculated as the ratio of sum of droplet-free filament size to cloud core width, which is estimated as the product of the aircraft observation time in an individual cloud and the aircraft speed. It is evident from Figure 6 that $\psi_{1}-\psi_{0.1}$ and $\psi_{1} / \psi_{0.1}$ decrease with increasing mean droplet-free filament size, sum of droplet-free filament size, and droplet-free filament fraction. Moreover, the correlation coefficients with the droplet-free filament fraction $\left(-0.36\right.$ for $\psi_{1}-\psi_{0.1}$ and -0.51 for $\left.\psi_{1} / \psi_{0.1}\right)$ are slightly larger than with the mean ( -0.35 for $\psi_{1}-\psi_{0.1}$ and -0.48 for $\left.\psi_{1} / \psi_{0.1}\right)$ and sum $\left(-0.30\right.$ for $\psi_{1}-\psi_{0.1}$ and -0.41 for $\left.\psi_{1} / \psi_{0.1}\right)$ of droplet-free filament sizes, suggesting that the droplet-free fraction captures the effect of droplet-free filaments better than the mean and sum of droplet-free filament sizes. It is noteworthy that the droplet-free filament fraction could be thought of representing the first-order cloud heterogeneity.

A few apparent exceptions are worth noting. Four cumulus clouds (the four overlapped dots in the upper left corner of each panel in Figure 6) have $\psi_{1}-\psi_{0.1}$ equal to 0 and $\psi_{1} / \psi_{0.1}$ 
equal to 1. Further analysis indicates that the mean droplet-free filament size, sum of droplet-free filament size, and droplet-free filament fraction of these clouds are all zero, suggesting that no droplet-free filaments exist in these clouds. Six clouds have $\psi_{1}-\psi_{0.1}$ larger than 0 and $\psi_{1} / \psi_{0.1}$ larger than 1 . The behaviors of these clouds could be related to uncertainties in the estimation of $\mathrm{LWC}_{\mathrm{a}}, r_{\mathrm{va}}$ and $n_{\mathrm{a}}$, and measurement errors of temperature, water vapor mixing ratio and liquid water content. One cloud has $\psi_{1}-\psi_{0.1}$ larger than 0 and $\psi_{1} / \psi_{0.1}$ smaller than 1 , which could also be caused by uncertainties as mentioned above; another possibility is inhomogeneous mixing with subsequent ascent, as discussed in Section 3. Collision-coalescence is not likely because the maximum mean volume radius is only 4.2 $\mu \mathrm{m}$ in this cloud.

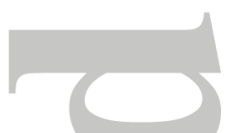

4.2.3 Effect of cloud microphysics on scale dependence

To explore the sensitivity of scale dependence to cloud microphysics, Figure 7 shows the relationships of (a) $\psi_{1}-\psi_{0.1}$ and (b) $\psi_{1} / \psi_{0.1}$ vs. $r_{\mathrm{vf}}{ }^{3} / r_{\mathrm{vc}}{ }^{3}$, where $r_{\mathrm{vf}}$ is the mean value of mean volume radius of CDSDs adjacent to droplet-free filaments in a cloud; $r_{\mathrm{vc}}$ is the mean value of mean volume radius of all CDSDs in a cloud. One CDSD from each side (left and right) of a filament is taken in the calculation of $r_{\mathrm{vf}}$, so in total two CDSDs are used. Four clouds without filament structure are excluded in the analysis. Similar to Figure 7, Figure 8 shows the relationships of (a) $\psi_{1}-\psi_{0.1}$ and (b) $\psi_{1} / \psi_{0.1}$ vs. $\mathrm{LWC}_{\mathrm{f}} / \mathrm{LWC}_{\mathrm{c}}$, where $\mathrm{LWC}_{\mathrm{f}}$ is the mean value of liquid water content of CDSDs adjacent to droplet-free filaments in a cloud, and $\mathrm{LWC}_{\mathrm{c}}$ is the mean value of liquid water content of all CDSDs in a cloud. The negative relationships indicate that mean volume radius and liquid water content of CDSDs adjacent to droplet-free 
filaments play important roles in determining scale dependence of entrainment-mixing mechanisms.

To further examine the sensitivities of the relationships in Figures 7 and 8 to the $r_{\mathrm{vf}}$ and $\mathrm{LWC}_{\mathrm{f}}$ uncertainties, we also use four CDSDs instead of two CDSDs for each filament to calculate $r_{\mathrm{vf}}$ and $\mathrm{LWC}_{\mathrm{f}}$, i.e., two CDSDs from each side (left and rigreht) of a filament are used. The results are almost the same as those in Figures 7 and 8 (not shown).

Note that majority of $\mathrm{LWC}_{\mathrm{f}}$ is smaller than $\mathrm{LWC}_{\mathrm{c}}$ as expected from dilution and evaporation during entrainment-mixing processes. $\mathrm{LWC}_{\mathrm{f}}$ could also be partially reduced due to the droplet-free filaments smaller than $\sim 5 \mathrm{~m}$. According to Burnet and Brenguier [2007], in situ measurements of $r_{\mathrm{vf}}$ tend to disguise the lowest $r_{\mathrm{v}}$ values in a spatially heterogeneous sample with the droplet-free filaments smaller than $\sim 5 \mathrm{~m}$. But still, $r_{\mathrm{vf}}$ is generally smaller than $r_{\mathrm{vc}}$, because the entrainment-mixing mechanisms are close to homogeneous at high resolutions, as shown in Figure 3.

Since $\psi_{1}-\psi_{0.1}$ and $\psi_{1} / \psi_{0.1}$ are negatively correlated with microphysics $\left(r_{\mathrm{vf}}{ }^{3} / r_{\mathrm{vc}}{ }^{3}\right.$ and $\left.\mathrm{LWC}_{\mathrm{f}} / \mathrm{LWC}_{\mathrm{c}}\right)$ and $F$, respectively, it is important to check if microphysical properties $\left(r_{\mathrm{vf}}^{3} / r_{\mathrm{vc}}{ }^{3}\right.$ and $\mathrm{LWC}_{\mathrm{f}} / \mathrm{LWC}_{\mathrm{c}}$ ) and $F$ are dependent. As shown in Figure 9, the relationships of microphysical properties $\left(r_{\mathrm{vf}}^{3} / r_{\mathrm{vc}}{ }^{3}\right.$ and $\left.\mathrm{LWC}_{\mathrm{f}} / \mathrm{LWC}_{\mathrm{c}}\right)$ with $F$ are weak. So the microphysical properties and $F$ are largely two independent factors. On the other hand, $r_{\mathrm{vf}}{ }^{3} / r_{\mathrm{vc}}{ }^{3}$ and $\mathrm{LWC}_{\mathrm{f}} / \mathrm{LWC}_{\mathrm{c}}$ are related to each other with a strong positive correlation. So only one property $\left(\mathrm{LWC}_{\mathrm{f}} / \mathrm{LWC}_{\mathrm{c}}\right)$ is used in the further analysis because $\mathrm{LWC}_{\mathrm{f}} / \mathrm{LWC}_{\mathrm{c}}$ has larger correlation coefficients than $r_{\mathrm{vf}}{ }^{3} / r_{\mathrm{vc}}{ }^{3}$ with $\psi_{1}-\psi_{0.1}$ and $\psi_{1} / \psi_{0.1}$ (Figures 7 and 8). Multivariable regression is then used to seek the combined effects of microphysics and $F$ : 


$$
\psi_{1}-\psi_{0.1}=-0.004960 F-0.09966 \frac{\mathrm{LWC}_{\mathrm{f}}}{\mathrm{LWC}_{\mathrm{c}}}
$$

where the coefficient of determination $\left(\mathrm{R}^{2}\right)$ is 0.42 with the $p$ value smaller than 0.0001 . Similarly, $\psi_{1} / \psi_{0.1}$ can be expressed as:

$$
\frac{\psi_{1}}{\psi_{0.1}}=1-0.01727 F-0.7572 \frac{\mathrm{LWC}_{\mathrm{f}}}{\mathrm{LWC}_{\mathrm{c}}},
$$

where the $\mathrm{R}^{2}$ is 0.39 with the $p$ value smaller than 0.0001 .

Because linear regressions are used in Figures $6 e, 7 a$ and $8 a$, the $R^{2}$ in these figures are equal to the squared correlation coefficients, i.e., $0.13,0.10$ and 0.11 , respectively. These squared correlation coefficients are much smaller than the $\mathrm{R}^{2}$ in equation (9). The $\mathrm{R}^{2}$ in Figures $6 f, 7 b$ and $8 b$ are $0.26,0.12$ and 0.15 , respectively, much smaller than the $R^{2}$ in equation (10). A comparison of the coefficients of determination reveals that the two variable fitting is better than either of the single variable fitting. Therefore the combined effects of microphysics and $F$ are more significant on the scale dependence than the effect of each single factor (microphysics or $F$ ).

4.2.4 Effect of relative humidity

As discussed in Section 4.1, another factor that affects the scale dependence of the entrainment mixing processes is the relative humidity of the entrained air. Figure 10 shows that both $\psi_{1}$ and $\psi_{0.1}$ increase with increasing relative humidity in the entrained dry air, which is assumed from $D$ to $2 D$ away from the edge of the cloud core. From left to right, the eight points in this figure correspond to $D=500,300,100,50,40,30,20$ and $10 \mathrm{~m}$, respectively. When the relative humidity is higher, evaporation is slower and homogeneous mixing is more 
likely to occur, i.e., larger homogeneous mixing degree. Figure 11 further shows that $\psi_{1}-\psi_{0.1}$ and $\psi_{1} / \psi_{0.1}$ decrease with an increase in relative humidity. The effect of relative humidity on the scale dependence can be explained as follows. If relative humidity is higher, a greater proportion of dry air is required (i.e. smaller $\chi$ ) in order to reduce liquid water content from the adiabatic value to the observed one. So for higher relative humidity, State 2 should move leftwards, farther from State 1 in Figure 1 . As a result, the length $m_{2}$ becomes smaller; homogeneous mixing degree and its variation $\left(\psi_{1}-\psi_{0.1}\right.$ and $\left.\psi_{1} / \psi_{0.1}\right)$ increase, other conditions being equal. To more quantitatively examine the effect of relative humidity, equation (1) is differentiated:

$$
\frac{\partial \psi}{\partial \chi}=-\frac{\left(1-C_{1}\right) C_{2}}{\left(\chi-C_{2}\right)^{2}}
$$

where

$$
\begin{gathered}
C_{1}=\frac{r_{\mathrm{vc}}^{3}}{r_{\mathrm{va}}^{3}}, \\
C_{2}=\frac{\mathrm{LWC}_{\mathrm{c}}}{\mathrm{LWC}_{\mathrm{a}}} .
\end{gathered}
$$

A smaller $\chi$ means a larger value of $\frac{\left(1-C_{1}\right) C_{2}}{\left(\chi-C_{2}\right)^{2}}$ and a larger absolute value of $\partial \psi / \partial \chi$, others being equal. Therefore, $\psi_{1}-\psi_{0.1}$ and $\psi_{1} / \psi_{0.1}$ are larger for higher relative humidity, suggesting that high relative humidity of entrained air can enhance the scale dependence of entrainment-mixing mechanisms. Ideally, when the relative humidity is $100 \%$, both the denominator and numerator in equation (11a) are equal to 0 . In this case, there is no need to distinguish between entrainment-mixing mechanisms, as pointed out in previous studies [e.g., Lehmann et al., 2009]. 
5 Concluding remarks

The scale dependence of entrainment-mixing mechanisms is examined using the data collected from shallow cumuli during the RACORO field campaign. A new measure of homogeneous mixing degree is defined based on the relationship between cubic mean volume radius and liquid water content, normalized by their own adiabatic values, respectively. Homogeneous mixing degree decreases significantly when the averaging time window increases from $0.1 \mathrm{~s}$ to $60 \mathrm{~s}$, and such a variation can be well fitted by exponential functions.

The base of the exponential function is close to a constant of 0.90 for different sources of entrained dry air. The adiabatic cloud core assumption and the measurement errors of temperature, water vapor mixing ratio and liquid water content are examined and the results indicate small effects on the calculated homogeneous mixing degree.

The strength of the scale dependence as measured by the difference $\psi_{1}-\psi_{0.1}$ and ratio $\psi_{1} / \psi_{0.1}$ are further used to study factors influencing the scale dependence, where $\psi_{1}$ and $\psi_{0.1}$ are homogeneous mixing degree for $1 \mathrm{~Hz}$ data and $10 \mathrm{~Hz}$ data, respectively. Three factors are found to be important in determining the strength of scale dependence. The first is droplet-free filament properties. $\psi_{1}-\psi_{0.1}$ and $\psi_{1} / \psi_{0.1}$ are both negatively correlated with mean droplet-free filament size, sum of droplet-free filament size and droplet-free filament fraction, respectively. Among the three properties, droplet-free filament fraction captures the effect of droplet-free filaments the best. The strong influence of the droplet-free filaments is further reinforced by the fact that the four clouds that do not have filament structures are found to have no scale dependence. The second factor is mean volume radius or liquid water content 
of cloud droplet size distributions (CDSDs) adjacent to droplet-free filaments. $\psi_{1}-\psi_{0.1}$ and $\psi_{1} / \psi_{0.1}$ are, respectively, negatively correlated with $r_{\mathrm{vf}}^{3} / r_{\mathrm{vc}}{ }^{3}$ and $\mathrm{LWC}_{\mathrm{f}} / \mathrm{LWC}_{\mathrm{c}}$, where $r_{\mathrm{vf}}$ and $\mathrm{LWC}_{\mathrm{f}}$ are, respectively, the mean values of mean volume radius and liquid water content of CDSDs adjacent to droplet-free filaments in a cloud, and $r_{\mathrm{vc}}$ and $\mathrm{LWC}_{\mathrm{c}}$ are, respectively, the mean values of mean volume radius and liquid water content of all CDSDs in a cloud. The third is relative humidity in the entrained dry air. High relative humidity can enhance the scale dependence, consistent with theoretical analysis.

Several points are noteworthy. First, Lu et al. [2013b, 2014] explored parameterizations

of entrainment-mixing mechanisms in cumulus and stratocumulus clouds with aircraft observations and numerical simulations. This study suggests that it is important to consider the scale dependence in the parameterizations of entrainment-mixing mechanisms. Second, the sampling rate is $10 \mathrm{~Hz}$; data with a higher sampling rate could bring more insights on the scale dependence of entrainment-mixing mechanisms. Third, the droplet-free filament size used in this study is one dimensional because the aircraft observation collects data along its own track, while the droplet-free filament in nature is three dimensional. This could add noise to the relationships in Figure 6. Gerber et al. [2005] applied a statistical method to aircraft observational data to study hole size, which is conceptually similar to droplet-free filament though there could be droplets in holes. Except statistical methods, numerical simulations (e.g., direct numerical simulations) could be an important tool to study this topic. Finally, this study just scratches the surface of the scale dependence of entrainment-mixing processes, and more research is definitely needed. For example, on average, the homogeneous mixing degree in the cumulus clouds examined here appears to be larger than that in stratocumulus 
clouds collected at the same location [Lu et al., 2013b]. Future study will examine the difference in the scale dependence to improve our understanding of the effects of thermodynamics, dynamics and microphysics.

Acknowledgements This research was supported by the National Natural Science Foundation of China (41305120, 41030962, 41375138, 41275151); the Natural Science

Foundation of Jiangsu Province, China (BK20130988); the Specialized Research Fund for the

Doctoral Program of Higher Education (20133228120002); the Natural Science Foundation

of the Higher Education Institutions of Jiangsu Province, China (13KJB170014); China Meteorological Administration Special Public Welfare Research Fund (GYHY201406007); the Open Funding from State Key Laboratory of Numerical Modeling for Atmospheric Sciences and Geophysical Fluid Dynamics; the Open Funding from Key Laboratory of Meteorological Disaster of Ministry of Education, China (KLME1305); the Qing-Lan Project; a Project Funded by the Priority Academic Program Development of Jiangsu Higher Education Institutions; the U.S. Department of Energy's (DOE) Earth System Modeling (ESM) program via the FASTER project (www.bnl.gov/faster) and Atmospheric System Research (ASR) program. Data used in this article are from the U.S. Department of Energy ARM Aerial Facility's RACORO Campaign (http://www.arm.gov/). We appreciate the helpful discussions about the data with Drs. Andrew Vogelmann, Haf Jonsson, Gunnar Senum, Greg McFarquhar and Hee-Jung Yang. We also appreciate Dr. Glenn Diskin's help on the data from DLH. 


\section{References}

Andrejczuk, M., W. W. Grabowski, S. P. Malinowski, and P. K. Smolarkiewicz (2009), Numerical simulation of cloud-clear air interfacial mixing: Homogeneous versus inhomogeneous mixing, J. Atmos. Sci., 66(8), 2493-2500, doi:10.1175/2009JAS2956.1.

Baker, M. B., R. G. Corbin, and J. Latham (1980), The influence of entrainment on the evolution of cloud droplet spectra: I. A model of inhomogeneous mixing, Q. J. Roy. Meteor. Soc., 106(449), 581-598, doi:10.1002/qj.49710644914.

Baker, M. B., R. E. Breidenthal, T. W. Choularton, and J. Latham (1984), The effects of turbulent mixing in clouds, J. Atmos. Sci., 41(2), 299-304, doi:10.1175/1520-0469(1984)041<0299:TEOTMI>2.0.CO;2.

Blyth, A. M. (1993), Entrainment in cumulus clouds, J. Appl. Meteorol., 32(4), 626-641, doi: 10.1175/1520-0450(1993)032<0626:eicc>2.0.co;2.

Bony, S., and J.-L. Dufresne (2005), Marine boundary layer clouds at the heart of tropical cloud feedback uncertainties in climate models, Geophys. Res. Lett., 32(20), L20806, doi:10.1029/2005g1023851.

Burnet, F., and J. L. Brenguier (2007), Observational study of the entrainment-mixing process in warm convective clouds, J. Atmos. Sci., 64(6), 1995-2011, doi:10.1175/JAS3928.1.

Cess, R. D., et al. (1989), Interpretation of cloud-climate feedback as produced by 14 atmospheric general circulation models, Science, 245(4917), 513-516, doi:10.1126/science.245.4917.513.

Chosson, F., J.-L. Brenguier, and L. Schüller (2007), Entrainment-mixing and radiative 
transfer simulation in boundary layer clouds, J. Atmos. Sci., 64(7), 2670-2682, doi:10.1175/JAS3975.1.

Clothiaux, E. E., T. P. Ackerman, G. G. Mace, K. P. Moran, R. T. Marchand, M. A. Miller, and B. E. Martner (2000), Objective determination of cloud heights and Radar reflectivities using a combination of active remote sensors at the ARM CART sites, $J$. Appl. Meteorol., 39(5), 645-665.

de Rooy, W. C., P. Bechtold, K. Fröhlich, C. Hohenegger, H. Jonker, D. Mironov, A. Pier Siebesma, J. Teixeira, and J.-I. Yano (2013), Entrainment and detrainment in cumulus convection: an overview, Q. J. Roy. Meteor. Soc., 139(670), 1-19, 10.1002/qj.1959.

Del Genio, A. D., and J. Wu (2010), The role of entrainment in the diurnal cycle of continental convection, J. Climate, 23(10), 2722-2738, doi: 10.1175/2009JCLI3340.1.

Deng, Z., C. Zhao, Q. Zhang, M. Huang, and X. Ma (2009), Statistical analysis of microphysical properties and the parameterization of effective radius of warm clouds in Beijing area, Atmos. Res., 93(4), 888-896, doi:10.1016/j.atmosres.2009.04.011.

Devenish, B. J., et al. (2012), Droplet growth in warm turbulent clouds, Q. J. Roy. Meteor. Soc., 138, 1401-1429, doi: 10.1002/qj.1897.

Diskin, G. S., J. R. Podolske, G. W. Sachse, and T. A. Slate (2002), Open-path airborne tunable diode laser hygrometer, paper presented at Proceedings of SPIE, Seattle, WA, USA

Freud, E., D. Rosenfeld, M. O. Andreae, A. A. Costa, and P. Artaxo (2008), Robust relations between $\mathrm{CCN}$ and the vertical evolution of cloud drop size distribution in deep convective clouds, Atmos. Chem. Phys., 8(6), 1661-1675. 
Freud, E., D. Rosenfeld, and J. R. Kulkarni (2011), Resolving both entrainment-mixing and number of activated CCN in deep convective clouds, Atmos. Chem. Phys., 11(24), $12887-12900$.

Gerber, H., G. Frick, S. P. Malinowski, J.-L. Brenguier, and F. Burnet (2005), Holes and Entrainment in Stratocumulus, J. Atmos. Sci., 62(2), 443-459, doi:10.1175/JAS-3399.1.

Gerber, H. E., G. M. Frick, J. B. Jensen, and J. G. Hudson (2008), Entrainment, mixing, and microphysics in trade-wind cumulus, J. Meteorol. Soc. Japan, 86A, 87-106.

Ghan, S. J., et al. (2011), Droplet nucleation: Physically-based parameterizations and comparative evaluation, J. Adv. Model. Earth Sy., 3(4), M10001, 10.1029/2011MS000074.

Grabowski, W. W. (2006), Indirect impact of atmospheric aerosols in idealized simulations of convective-radiative quasi equilibrium, J. Climate, 19(18), 4664-4682, doi:10.1175/JCLI3857.1.

Haman, K. E., S. P. Malinowski, M. J. Kurowski, H. Gerber, and J.-L. Brenguier (2007), Small scale mixing processes at the top of a marine stratocumulus - a case study, $Q . J$. Roy. Meteor. Soc., 133(622), 213-226, doi:10.1002/qj.5.

Hill, A. A., G. Feingold, and H. Jiang (2009), The influence of entrainment and mixing assumption on aerosol-cloud interactions in marine stratocumulus, J. Atmos. Sci., $66(5), 1450-1464$.

Jarecka, D., W. W. Grabowski, H. Morrison, and H. Pawlowska (2013), Homogeneity of the subgrid-scale turbulent mixing in large-eddy simulation of shallow convection, $J$. 
Atmos. Sci., 70, 2751-2767.

Jensen, J. B., P. H. Austin, M. B. Baker, and A. M. Blyth (1985), Turbulent mixing, spectral evolution and dynamics in a warm cumulus cloud, J. Atmos. Sci., 42(2), 173-192, doi:10.1175/1520-0469(1985)042<0173:TMSEAD>2.0.CO;2.

Kim, B.-G., M. A. Miller, S. E. Schwartz, Y. Liu, and Q. Min (2008), The role of adiabaticity in the aerosol first indirect effect, J. Geophys. Res., 113(D5), D05210, doi: $10.1029 / 2007 \mathrm{jd} 008961$.

Krueger, S. K. (2008), Fine-scale modeling of entrainment and mixing of cloudy and clear air, paper presented at the 15th International Conference on Clouds and Precipitation, Cancun, Mexico.

Kumar, B., J. Schumacher, and R. Shaw (2012), Cloud microphysical effects of turbulent mixing and entrainment, Theor. Comp. Fluid Dyn., 1-16.

Lasher-Trapp, S. G., W. A. Cooper, and A. M. Blyth (2005), Broadening of droplet size distributions from entrainment and mixing in a cumulus cloud, Q. J. Roy. Meteor. Soc., 131(605), 195-220, doi:10.1256/qj.03.199.

Lehmann, K., H. Siebert, and R. A. Shaw (2009), Homogeneous and inhomogeneous mixing in cumulus clouds: dependence on local turbulence structure, J. Atmos. Sci., 66, 3641-3659, doi:10.1175/2009JAS3012.1.

Liu, Y., P. H. Daum, S. K. Chai, and F. Liu (2002), Cloud parameterizations, cloud physics, and their connections: An overview, Recent Res. Devel. Geophysics, 4, 119-142.

Liu, Y., P. Daum, H. Guo, and Y. Peng (2008), Dispersion bias, dispersion effect, and the aerosol-cloud conundrum, Environ. Res. Lett., 3, 045021. 
Lu, C., Y. Liu, and S. Niu (2011), Examination of turbulent entrainment-mixing mechanisms using a combined approach, J. Geophys. Res., 116, D20207, doi:10.1029/2011JD015944.

Lu, C., Y. Liu, S. Niu, and A. M. Vogelmann (2012a), Lateral entrainment rate in shallow cumuli: Dependence on dry air sources and probability density functions, Geophys. Res. Lett., 39(20), L20812, doi:10.1029/2012GL053646.

Lu, C., Y. Liu, S. Niu, and A. M. Vogelmann (2012b), Observed impacts of vertical velocity on cloud microphysics and implications for aerosol indirect effects, Geophys. Res. Lett., 39(21), L21808, doi:10.1029/2012GL053599.

Lu, C., Y. Liu, S. S. Yum, S. Niu, and S. Endo (2012c), A new approach for estimating entrainment rate in cumulus clouds, Geophys. Res. Lett., 39, L04802, doi:10.1029/2011GL050546.

Lu, C., Y. Liu, and S. Niu (2013a), A method for distinguishing and linking turbulent entrainment mixing and collision-coalescence in stratocumulus clouds, Chin. Sci. Bull., 58, 545-551, doi: 10.1007/s11434-012-5556-6.

Lu, C., Y. Liu, S. Niu, S. K. Krueger, and T. Wagner (2013b), Exploring parameterization for turbulent entrainment-mixing processes in clouds, J. Geophys. Res., 118, 185-194, doi:10.1029/2012JD018464.

Lu, C., Y. Liu, S. Niu, and A. M. Vogelmann (2013c), Empirical relationship between entrainment rate and microphysics in cumulus clouds, Geophys. Res. Lett., 40, 2333-2338, doi: 10.1002/grl.50445.

Lu, C., Y. Liu, and S. Niu (2014), Entrainment-mixing parameterization in shallow cumuli 
and effects of secondary mixing events, Chin. Sci. Bull., 59, 896-903.

Mann, J. A. L., J. Christine Chiu, R. J. Hogan, E. J. O'Connor, T. S. L'Ecuyer, T. H. M. Stein, and A. Jefferson (2014), Aerosol impacts on drizzle properties in warm clouds from ARM Mobile Facility maritime and continental deployments, J. Geophys. Res., 119(7), 2013JD021339, 10.1002/2013JD021339.

Morrison, H., and W. W. Grabowski (2008), Modeling supersaturation and subgrid-scale mixing with two-moment bulk warm microphysics, J. Atmos. Sci., 65(3), 792-812, doi:10.1175/2007JAS2374.1.

Paluch, I. R., and D. G. Baumgardner (1989), Entrainment and fine-scale mixing in a continental convective cloud, J. Atmos. Sci., 46(2), 261-278, doi:10.1175/1520-0469(1989)046<0261:EAFSMI>2.0.CO;2.

Pawlowska, H., J. L. Brenguier, and F. Burnet (2000), Microphysical properties of stratocumulus clouds, Atmos. Res., 55(1), 15-33.

Podolske, J. R., G. W. Sachse, and G. S. Diskin (2003), Calibration and data retrieval algorithms for the NASA Langley/Ames Diode Laser Hygrometer for the NASA Transport and Chemical Evolution Over the Pacific (TRACE-P) mission, J. Geophys. Res., 108(D20), 8792, doi: 10.1029/2002jd003156.

Romps, D. M., and Z. Kuang (2010), Nature versus nurture in shallow convection, J. Atmos. Sci., 67(5), 1655-1666, doi: 10.1175/2009JAS3307.1.

Slawinska, J., W. W. Grabowski, H. Pawlowska, and A. A. Wyszogrodzki (2008), Optical properties of shallow convective clouds diagnosed from a bulk-microphysics large-eddy simulation, J. Climate, 21(7), 1639-1647. 
Slawinska, J., W. W. Grabowski, H. Pawlowska, and H. Morrison (2012), Droplet activation and mixing in large-eddy simulation of a shallow cumulus field, J. Atmos. Sci., 69(2), 444-462.

Stephens, G. L. (2005), Cloud feedbacks in the climate system: A critical review, J. Climate, 18(2), 237-273, doi:10.1175/JCLI-3243.1.

Su, C.-W., S. K. Krueger, P. A. McMurtry, and P. H. Austin (1998), Linear eddy modeling of droplet spectral evolution during entrainment and mixing in cumulus clouds, Atmos. Res., 47-48, 41-58.

Vogelmann, A. M., et al. (2012), RACORO extended-term aircraft observations of boundary layer clouds, Bull. Am. Meteorol. Soc., 93(6), 861-878, doi: 10.1175/bams-d-11-00189.1.

von Salzen, K., and N. A. McFarlane (2002), Parameterization of the bulk effects of lateral and cloud-top entrainment in transient shallow cumulus clouds, J. Atmos. Sci., 59(8), 1405-1430, doi:10.1175/1520-0469(2002)059<1405:POTBEO>2.0.CO;2.

Wang, Z., H. Zhang, and P. Lu (2014), Improvement of cloud microphysics in the aerosol-climate model BCC_AGCM2.0.1_CUACE/Aero, evaluation against observations, and updated aerosol indirect effect, J. Geophys. Res., 119, 8400-8417.

Xue, H., and G. Feingold (2006), Large-eddy simulations of trade wind cumuli: Investigation of aerosol indirect effects, J. Atmos. Sci., 63(6), 1605-1622, 10.1175/jas3706.1.

Yum, S. (1998), Cloud droplet spectral broadening in warm clouds: An observational and model study, Dissertation for the Doctoral Degree thesis, University of Nevada, Reno, Nevada, USA. 
Zhang, G. J. (2009), Effects of entrainment on convective available potential energy and closure assumptions in convection parameterization, J. Geophys. Res., 114(D7), D07109, 10.1029/2008JD010976.

Zhang, H., X. Jing, and J. Li (2014), Application and evaluation of a new radiation code under McICA scheme in BCC_AGCM2.0.1, Geosci. Model Dev., 7, 737-754.

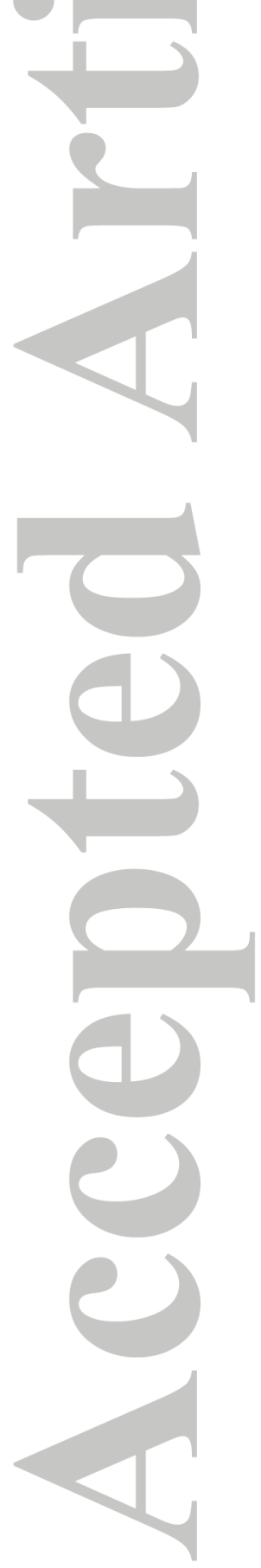




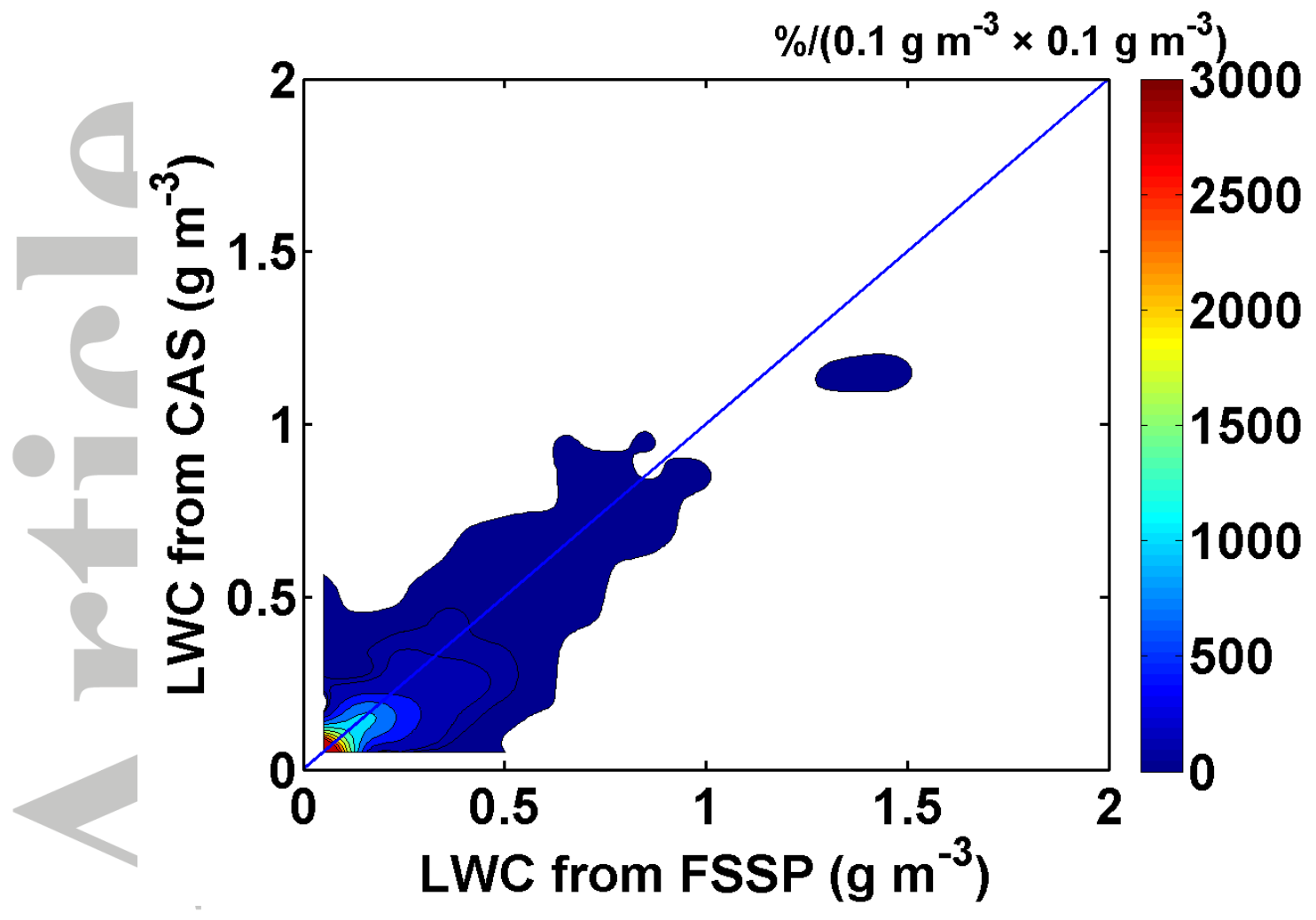

Figure 1 Liquid water content (LWC) from Cloud and Aerosol Spectrometer (CAS) as a function of LWC from Forward Scatter Spectrometer Probe (FSSP) in clouds of 8 flights during RACORO. The data frequency is $1 \mathrm{~Hz}$ and the number of samples is 5255 . The bin width is $0.1 \mathrm{~g} \mathrm{~m}^{-3}$.

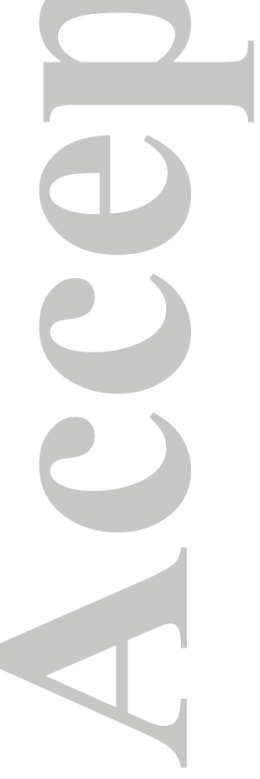




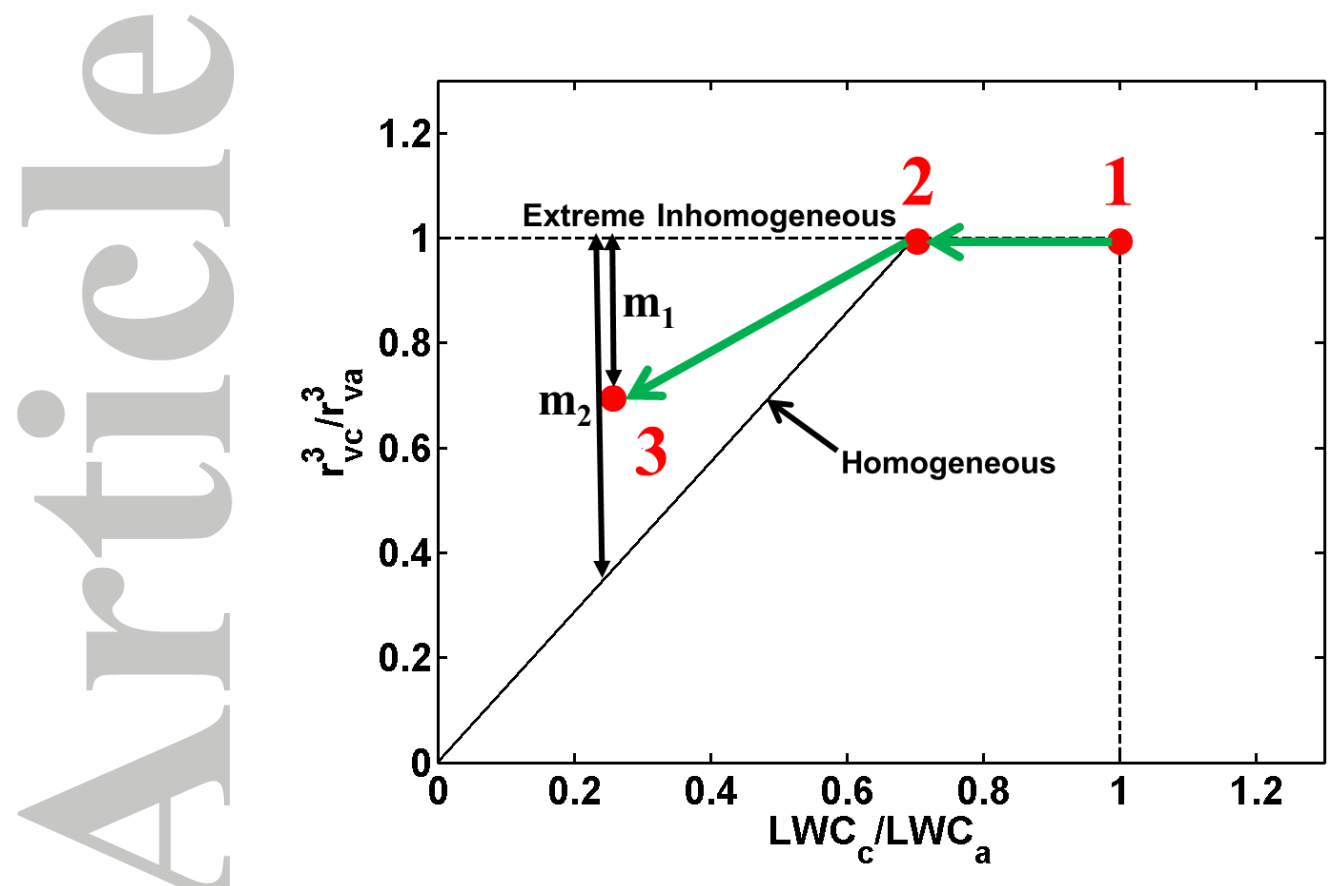

Figure 2 Diagram illustrating the definition of homogeneous mixing degree. The horizontal dash line represents extreme inhomogeneous mixing; the solid line corresponds to homogeneous mixing. See text for the meanings of the other lines and symbols.

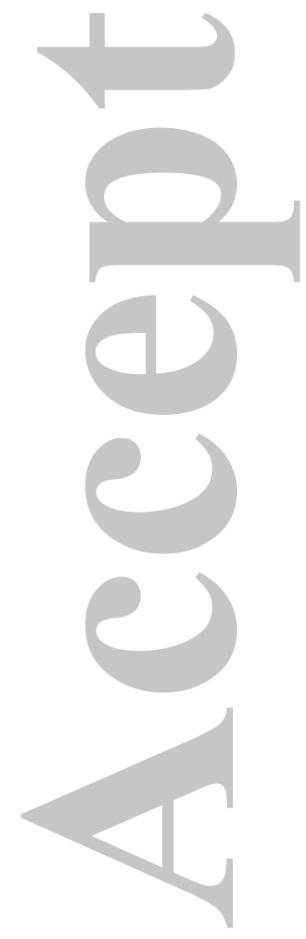



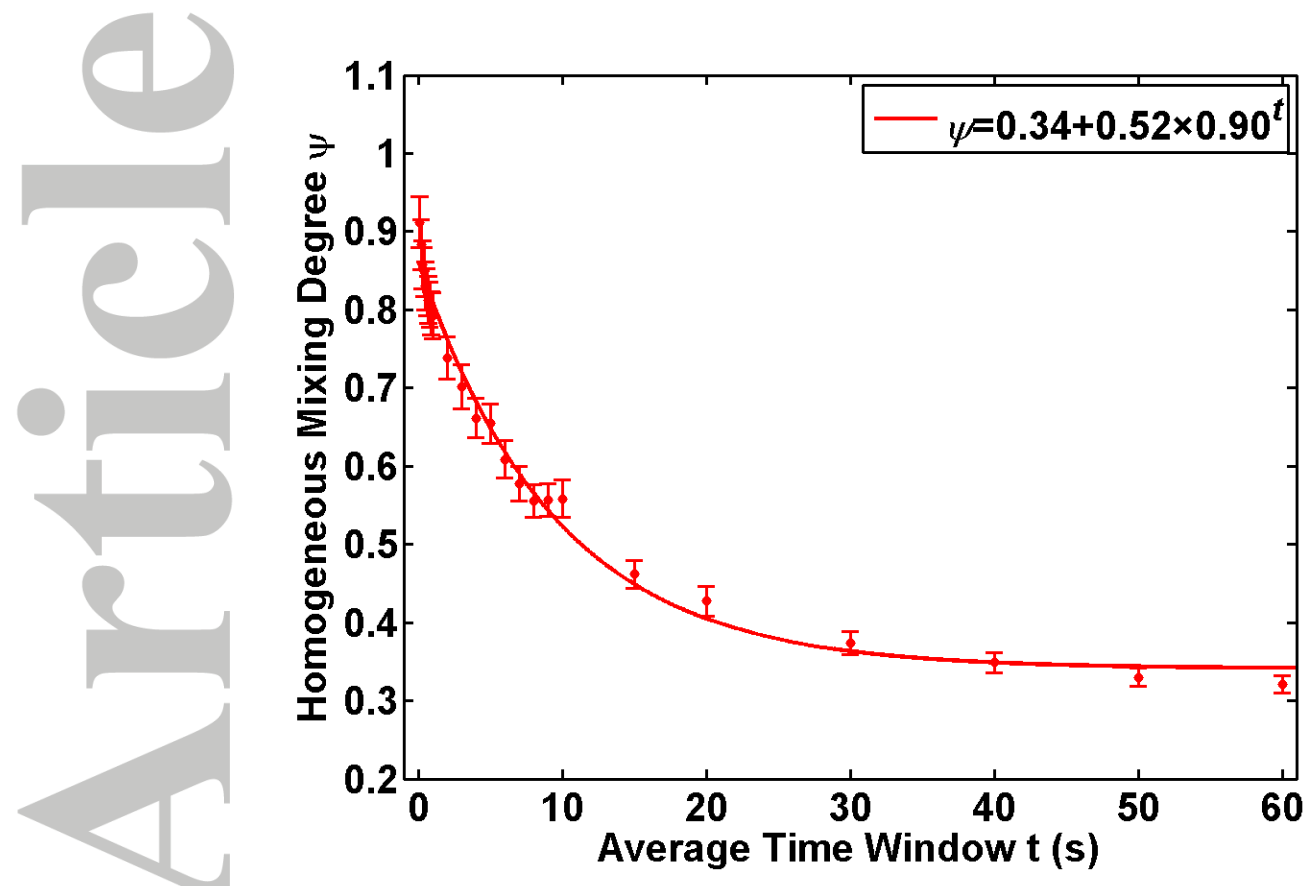

Figure 3 Homogeneous mixing degree $(\psi)$ as a function of averaging time window $(t)$ or averaging distance window in 186 growing cumulus clouds during RACORO. The dry air is assumed to be from $D$ to $2 D$ away from the edge of the cloud core; only the results for $D=$ $50 \mathrm{~m}$ are shown here. The legend provides the fitting function. The bars represent the standard errors of the mean homogeneous mixing degree. 

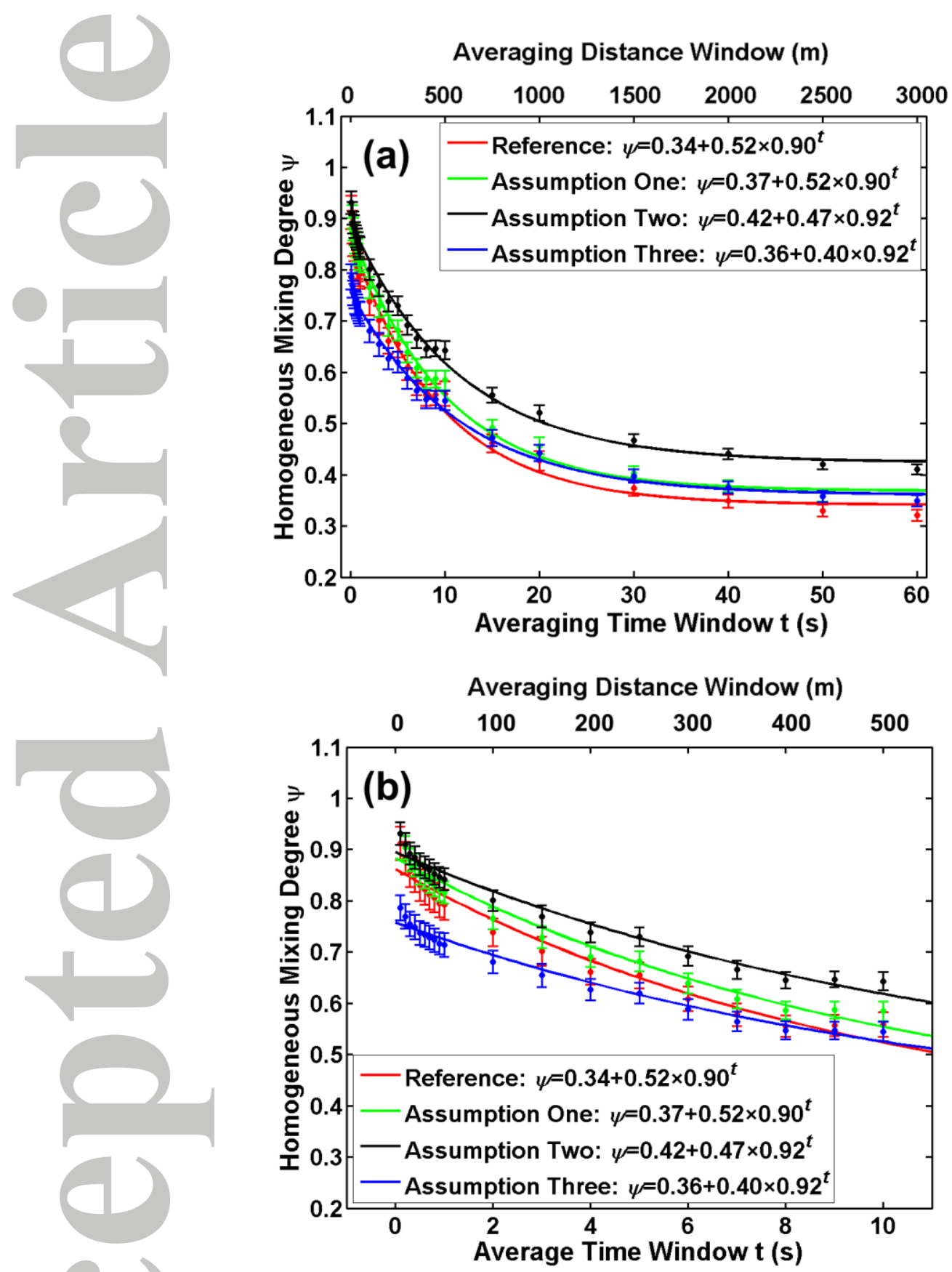

Figure 4 (a) Homogeneous mixing degree $(\psi)$ as a function of averaging time window $(t)$ or averaging distance window in 186 growing cumulus clouds during RACORO, assuming the true adiabatic liquid water content is 1.25 times of the observed maximum

liquid water content. (b) Enlarged version of the part of Figure 4a for $t<10 \mathrm{~s}$. Red line is the reference, the same as Figure 3. Assumption One is that the mean homogeneous 
mixing degree in the entrainment-mixing processes affecting assumed adiabatic cloud core $\left(\psi_{\mathrm{aa}}\right)$ for different $t$ is, respectively, the same as that shown in Figure 3. Assumption Two is that $\psi_{\mathrm{aa}}$ is equal to the maximum value of the mean homogeneous mixing degree $(\psi)$ in Figure 3, i.e., 0.92. Assumption Three is that $\psi_{\mathrm{aa}}$ is equal to the minimum value of the mean $\psi$ in Figure 3, i.e., 0.32. The legend provides the fitting functions. The bars represent standard errors of the mean homogeneous mixing degree. The dry air is assumed to be from $D$ to $2 D$ away from the edge of the cloud core, where here $D=50 \mathrm{~m}$.
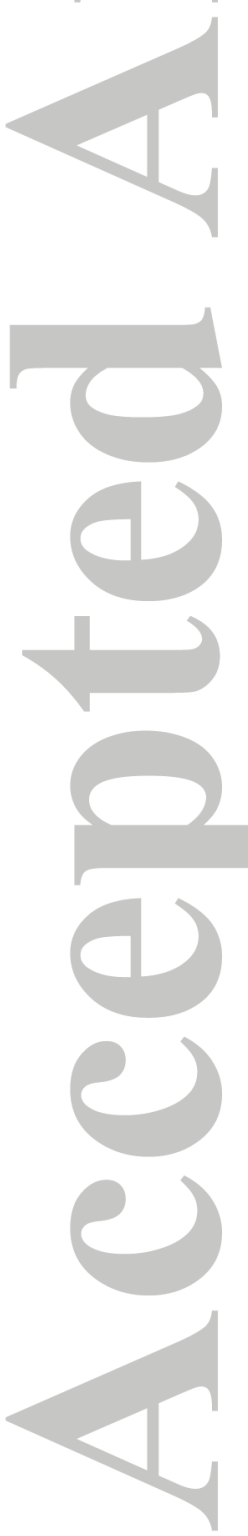

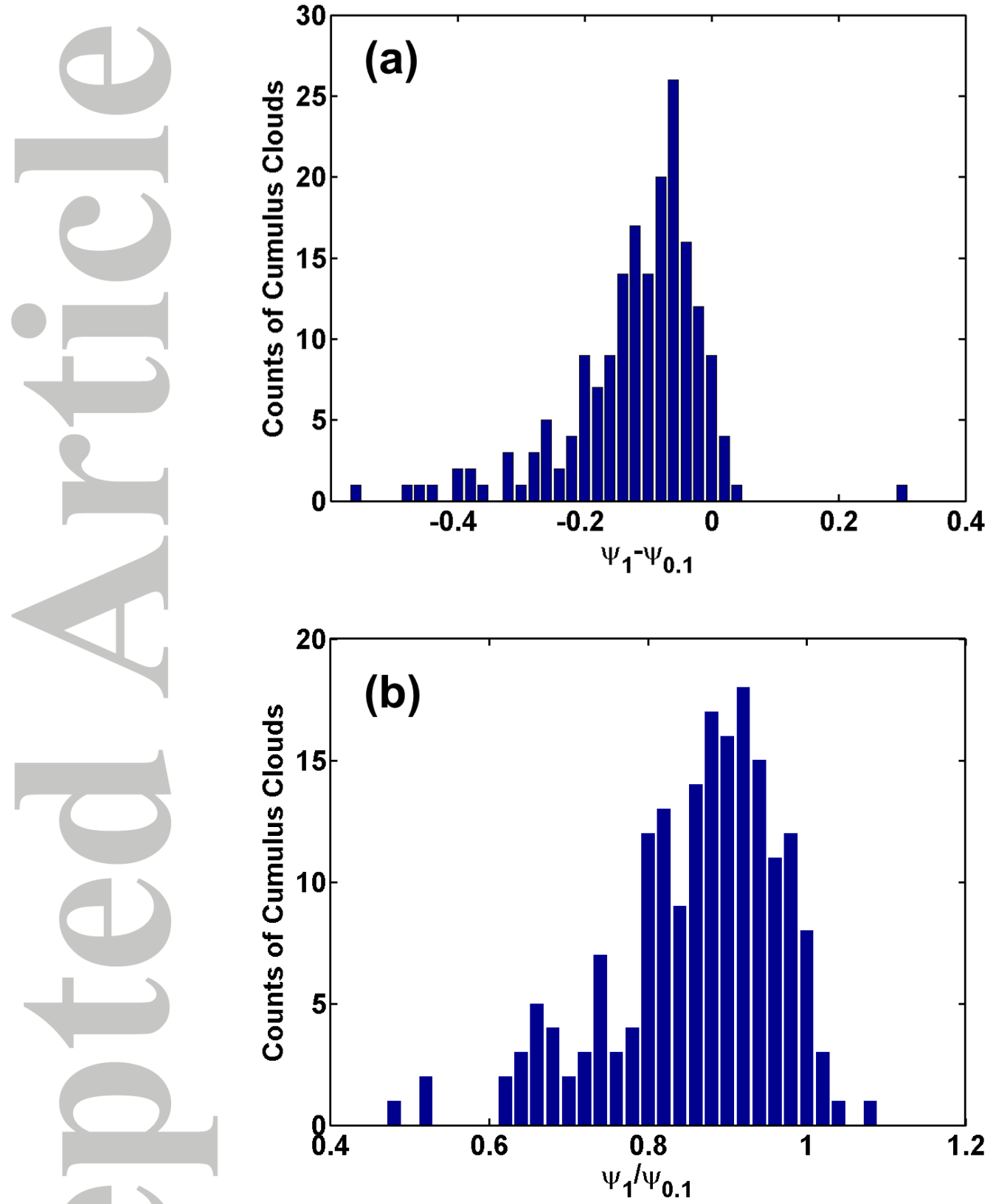

Figure 5 Probability density functions (PDFs) of (a) $\psi_{1}-\psi_{0.1}$ and (b) $\psi_{1} / \psi_{0.1}$ in 186 growing cumulus clouds during RACORO. The dry air is assumed to be from $D$ to $2 D$ away from the edge of the cloud core, where here $D=50 \mathrm{~m} . \psi_{0.1}$ and $\psi_{1}$ represent homogeneous mixing degrees for the $10 \mathrm{~Hz}$ original data and for the data averaged every $1 \mathrm{~s}$, respectively. 

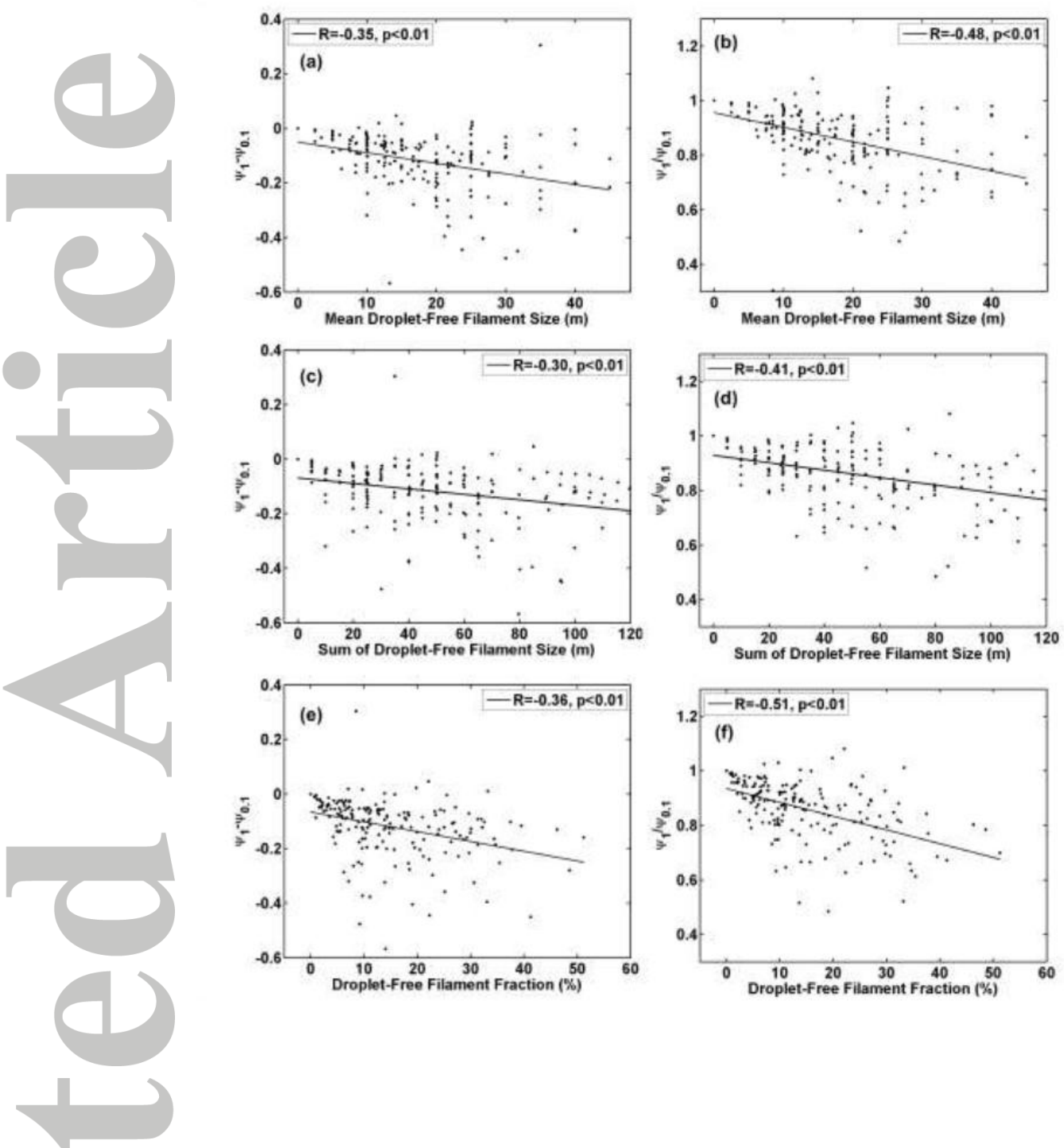

Figure $6 \quad \psi_{1}-\psi_{0.1}$ as a function of (a) mean droplet-free filament size, (c) sum of droplet-free filament size and (e) droplet-free filament fraction, respectively, in 186 growing cumulus clouds during RACORO. Figures b, $d$ and $f$ are the same as Figures a, c and e, respectively, but for $\psi_{1} / \psi_{0.1}$. The dry air is assumed to be from $D$ to $2 D$ away from the edge of the cloud core, where here $D=50 \mathrm{~m} . \psi_{0.1}$ and $\psi_{1}$ represent homogeneous mixing degrees for the $10 \mathrm{~Hz}$ original data and for the data averaged every $1 \mathrm{~s}$, respectively. 

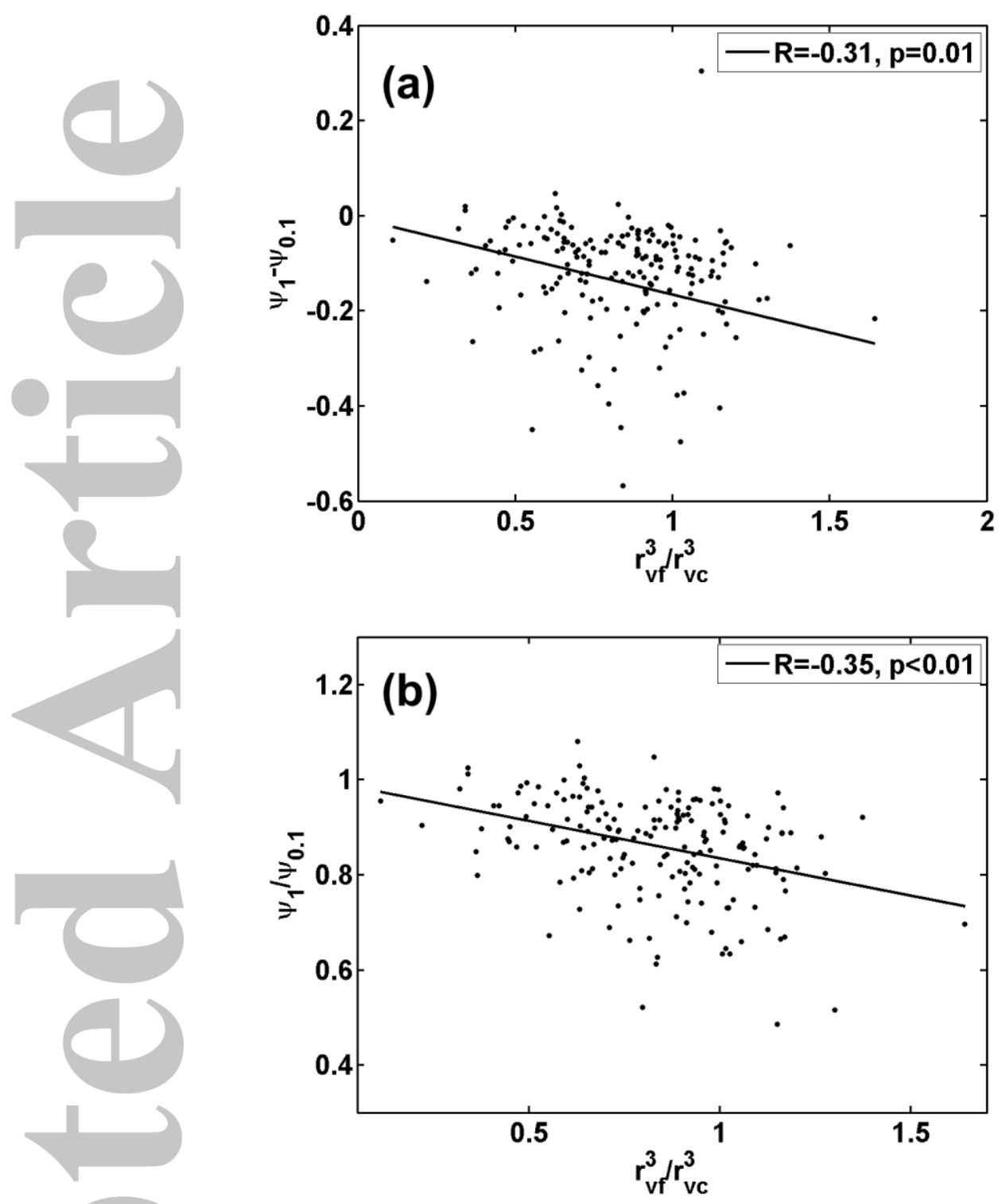

Figure 7 (a) $\psi_{1}-\psi_{0.1}$ as a function of $r_{\mathrm{vf}}{ }^{3} / r_{\mathrm{vc}}{ }^{3}$, and (b) $\psi_{1} / \psi_{0.1}$ as a function of $r_{\mathrm{vf}}{ }^{3} / r_{\mathrm{vc}}{ }^{3}$ in 186 growing cumulus clouds during RACORO. $\psi_{0.1}$ and $\psi_{1}$ represent homogeneous mixing degrees for the $10 \mathrm{~Hz}$ original data and for the data averaged every $1 \mathrm{~s}$, respectively. $r_{\mathrm{vf}}$ and $r_{\mathrm{vc}}$ represent mean values of mean volume radius in cloud droplet size distributions adjacent to droplet-free filaments and within a whole cloud, respectively. Each legend provides the correlation coefficient $(\mathrm{R})$ and the $p$ value of the correlation. The dry air is assumed to be from $D$ to $2 D$ away from the edge of the cloud core, where here $D=50 \mathrm{~m}$. 

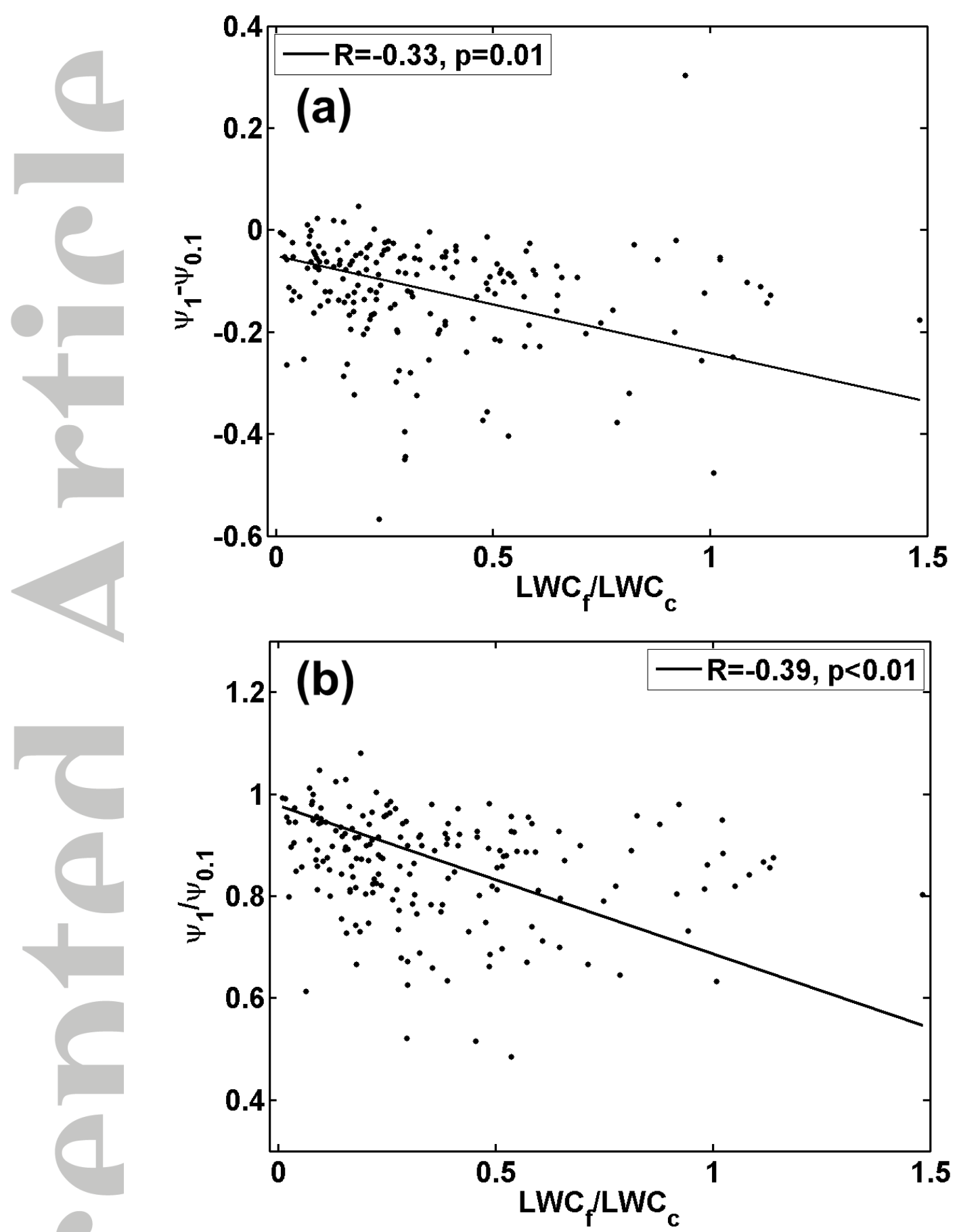

Figure 8 The same as Figure 7, but for (a) $\psi_{1}-\psi_{0.1}$ as a function of $\mathrm{LWC}_{\mathrm{f}} / \mathrm{LWC}_{\mathrm{c}}$, and (b) $\psi_{1} / \psi_{0.1}$ as a function of $\mathrm{LWC}_{\mathrm{f}} / \mathrm{LWC}_{\mathrm{c}} . \mathrm{LWC}_{\mathrm{f}}$ and $\mathrm{LWC}_{\mathrm{c}}$ represent mean values of liquid water content in cloud droplet size distributions adjacent to droplet-free filaments and within a whole cloud, respectively. 

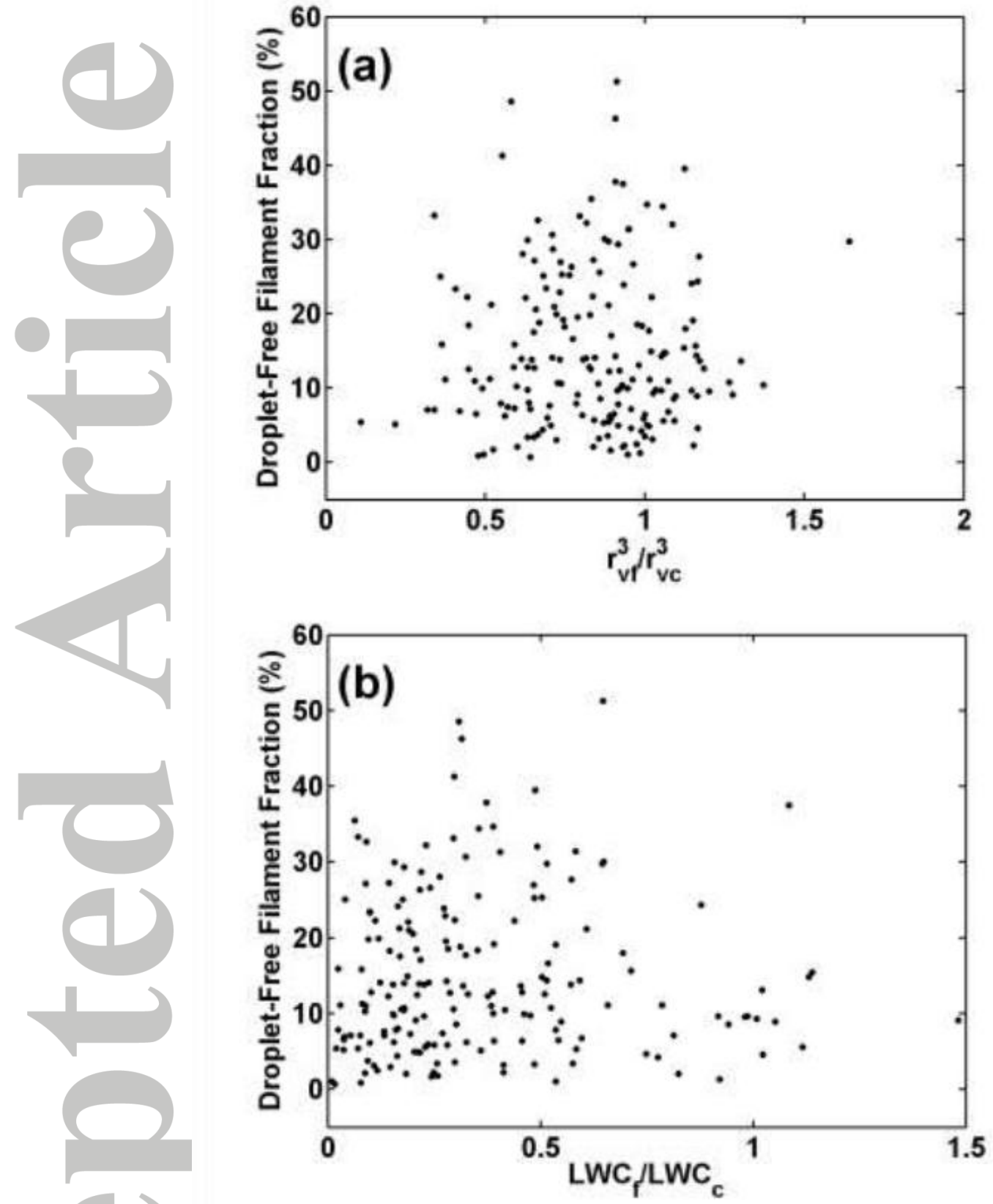

Figure 9 Droplet-free filament fraction as a function of (a) $r_{\mathrm{vf}}{ }^{3} / r_{\mathrm{vc}}{ }^{3}$ and (b) $\mathrm{LWC}_{\mathrm{f}} / \mathrm{LWC}_{\mathrm{c}}$ in 186 growing cumulus clouds during RACORO. $r_{\mathrm{vf}}$ and $r_{\mathrm{vc}}$ represent mean values of mean volume radius in cloud droplet size distributions adjacent to droplet-free filaments and within a whole cloud, respectively; $\mathrm{LWC}_{\mathrm{f}}$ and $\mathrm{LWC}_{\mathrm{c}}$ represent mean values of liquid water content in cloud droplet size distributions adjacent to droplet-free filaments and within a whole cloud, respectively. 


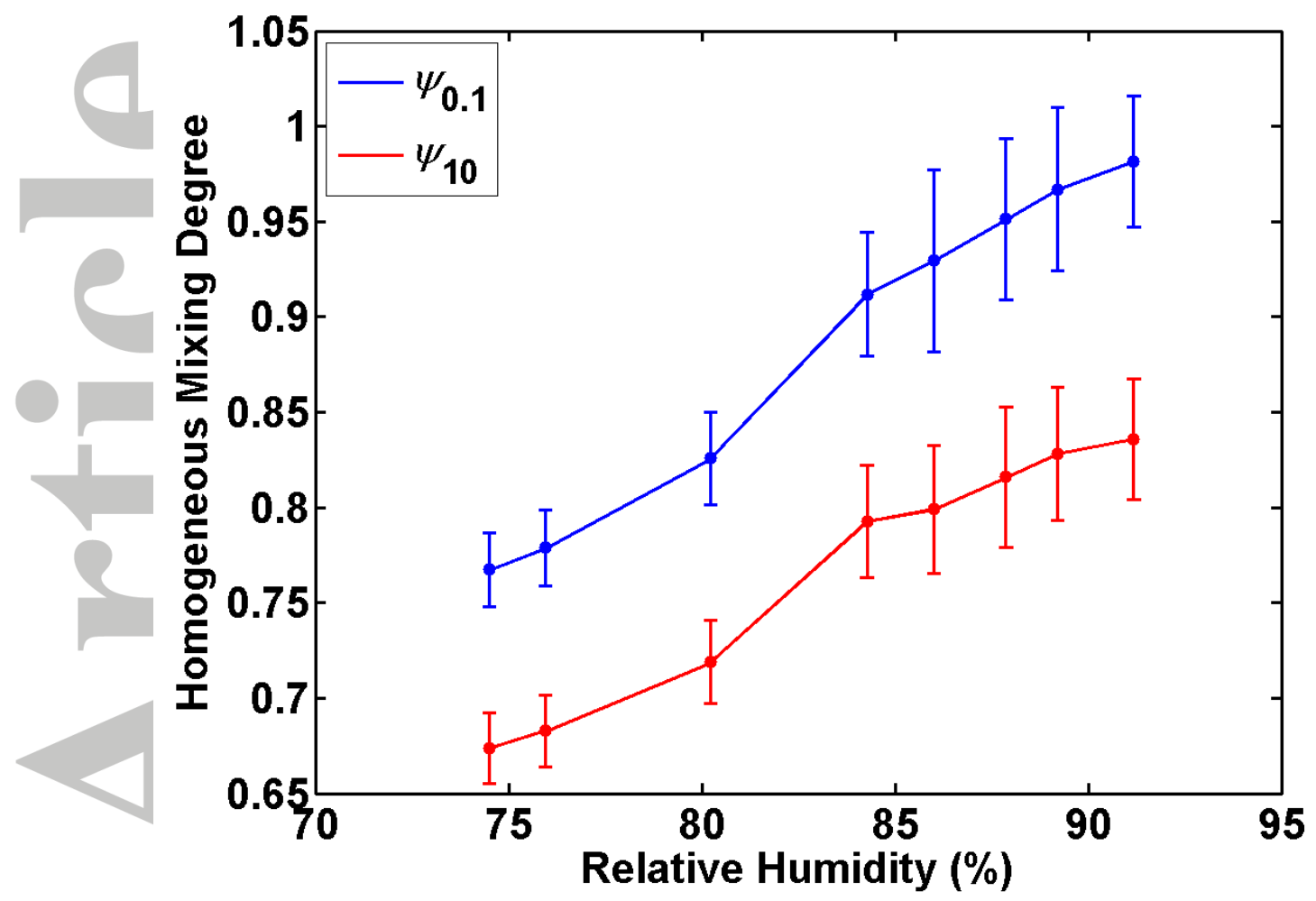

Figure 10 Homogeneous mixing degree as a function of relative humidity in the entrained dry air for different $D$ values in 186 growing cumulus clouds during RACORO. The dry air is assumed to be from $D$ to $2 D$ away from the edge of the cloud core. From left to right, the eight points in this figure correspond to $D=500,300,100,50,40,30,20$ and $10 \mathrm{~m}$, respectively. $\psi_{0.1}$ and $\psi_{1}$ represent homogeneous mixing degrees for the $10 \mathrm{~Hz}$ original data and for the data averaged every $1 \mathrm{~s}$, respectively. 

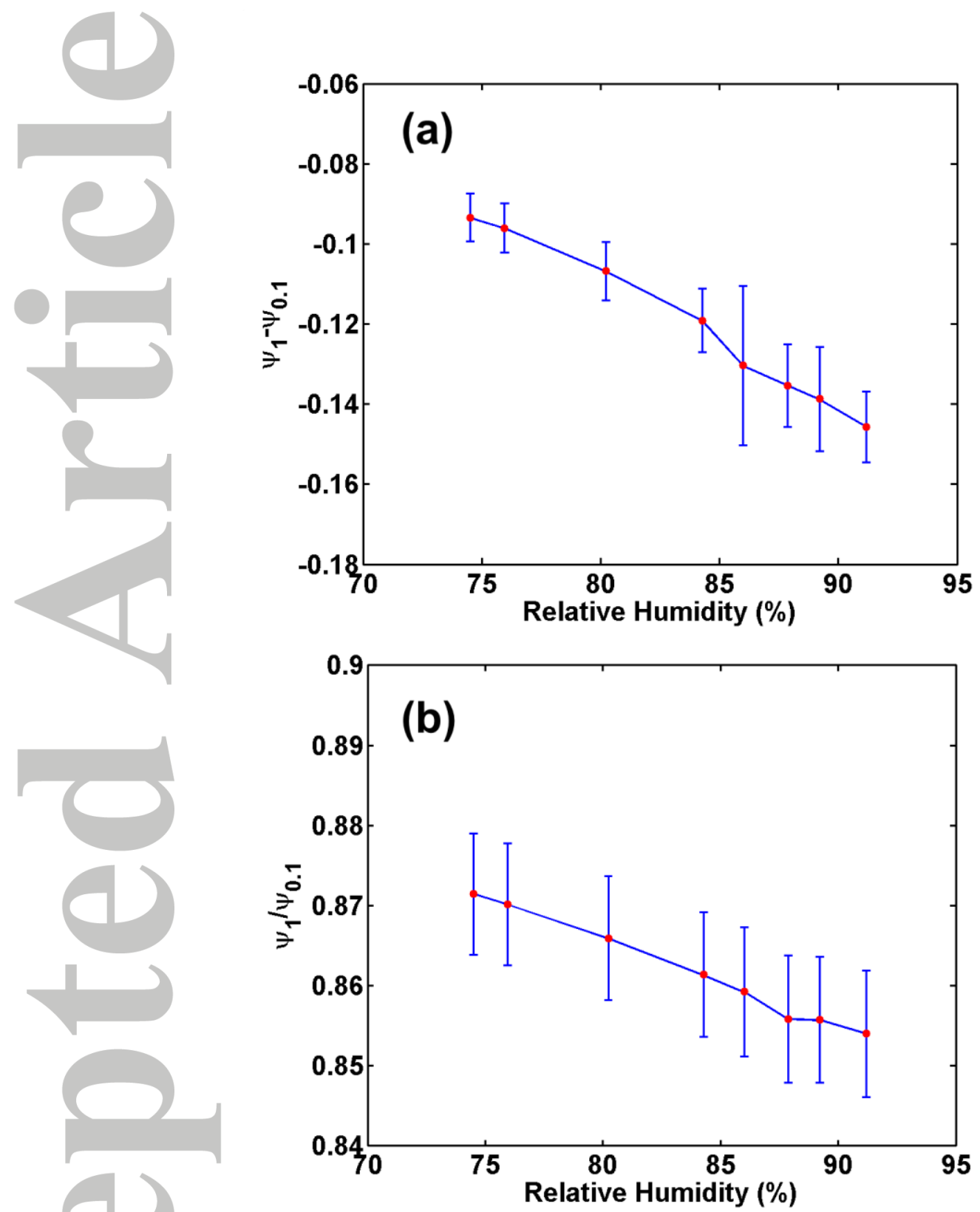

Figure 11 (a) $\psi_{1}-\psi_{0.1}$ and (b) $\psi_{1} / \psi_{0.1}$ as a function of relative humidity in the entrained dry air for different $D$ values in 186 growing cumulus clouds during RACORO. The dry air is assumed to be from $D$ to $2 D$ away from the edge of the cloud core. From left to right, the eight points in this figure correspond to $D=500,300,100,50,40,30,20$ and $10 \mathrm{~m}$, respectively. $\psi_{0.1}$ and $\psi_{1}$ represent homogeneous mixing degrees for the $10 \mathrm{~Hz}$ original data and for the data averaged every $1 \mathrm{~s}$, respectively. 